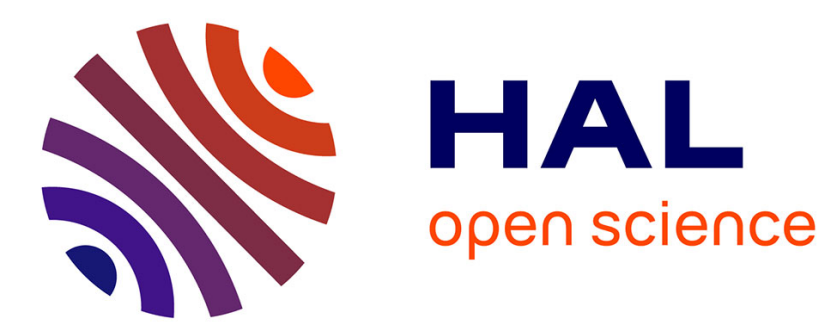

\title{
Omega-3 polyunsaturated lipophenols, how and why?
}

Céline Crauste, Mélissa Rosell, Thierry Durand, Joseph Vercauteren

\section{To cite this version:}

Céline Crauste, Mélissa Rosell, Thierry Durand, Joseph Vercauteren. Omega-3 polyunsaturated lipophenols, how and why?. Biochimie, 2015, 10.1016/j.biochi.2015.07.018 . hal-02309676

\section{HAL Id: hal-02309676 https://hal.science/hal-02309676}

Submitted on 9 Oct 2019

HAL is a multi-disciplinary open access archive for the deposit and dissemination of scientific research documents, whether they are published or not. The documents may come from teaching and research institutions in France or abroad, or from public or private research centers.
L'archive ouverte pluridisciplinaire HAL, est destinée au dépôt et à la diffusion de documents scientifiques de niveau recherche, publiés ou non, émanant des établissements d'enseignement et de recherche français ou étrangers, des laboratoires publics ou privés. 


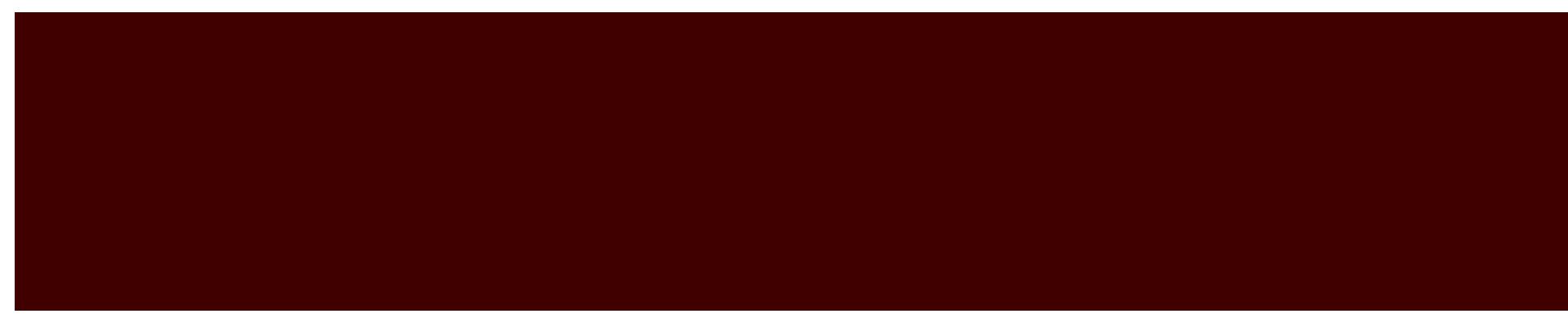

Review

\title{
Omega-3 polyunsaturated lipophenols, how and why?
}

\author{
Céline Crauste *, Mélissa Rosell, Thierry Durand, Joseph Vercauteren \\ Institute of Biomolecules Max Mousseron (IBMM), UMR 5247-CNRS-UM-ENSCM, Faculty of Pharmacy, 15 av. C. Flahault, 34093 Montpellier, France
}

\section{A R T I C L E I}

\section{Article history:}

Received 5 March 2015

Accepted 21 July 2015

Available online 23 July 2015

\section{Keywords:}

Lipophenol

PUFA

Omega-3

Polyphenol

Bioactivity

\begin{abstract}
A B S T R A C T
Polyphenols and n-3 polyunsaturated fatty acids (PUFAs) are two classes of natural compounds, which have been highlighted in epidemiological studies for their health benefits. The biological activities of those two families of metabolites on oxidation, inflammation, cancer, cardiovascular and degenerative diseases have been reported in vitro and in vivo. On the other hand, chemical bonding between the two structures leading to n-3 lipophenol derivatives (or phenolipids) has been studied in numerous works over the last decade, and some examples could also be found from natural sources. Interest in lipophilization of phenolic structures is various and depends on the domain of interest: in food industry, the development of lipidic antioxidants could be performed to protect lipidic food matrix from oxidation. Whereas, on pharmaceutical purpose, increasing the lipophilicity of polar phenolic drugs could be performed to improve their pharmacological profile. Moreover, combining both therapeutic aspects of n-3 PUFAs and of polyphenols in a single lipophenolic molecule could also be envisaged. An overview of the synthesis and of the natural sources of n-3 lipophenols is presented here, in addition to their biological activities which point out in several cases the benefit of the conjugated derivatives.
\end{abstract}

(C) 2015 Elsevier B.V. and Société Française de Biochimie et Biologie Moléculaire (SFBBM). All rights reserved.

\section{Contents}

1. Introduction

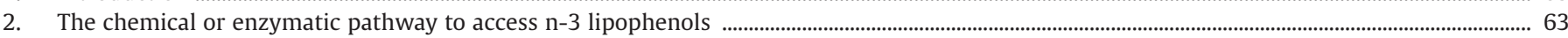

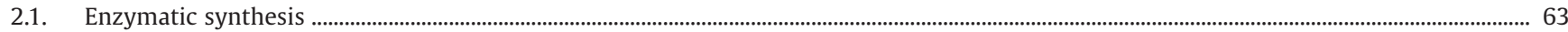

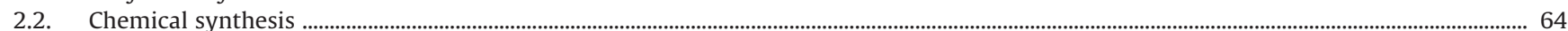

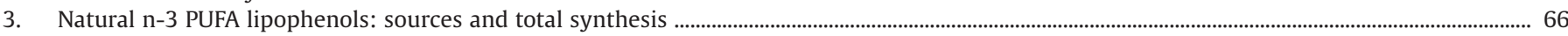

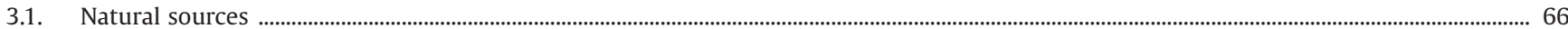

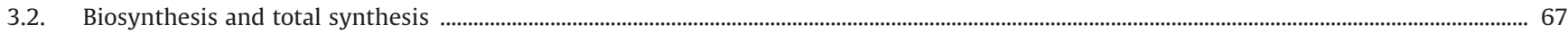

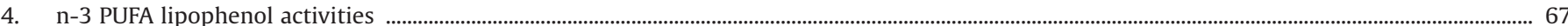

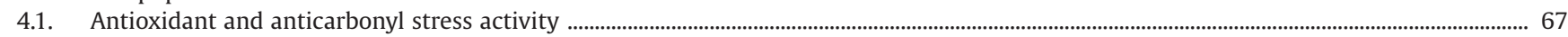

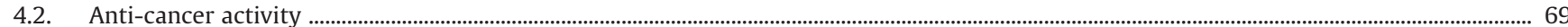

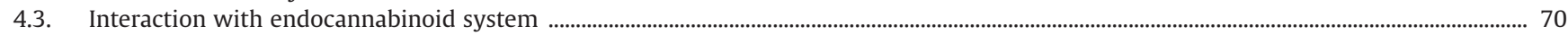

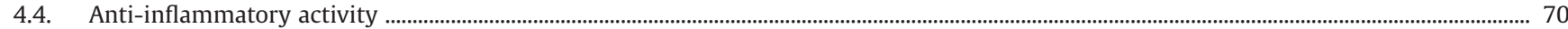

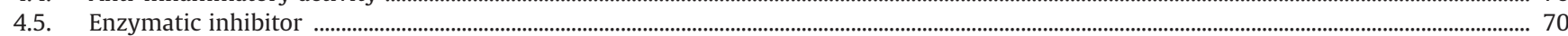

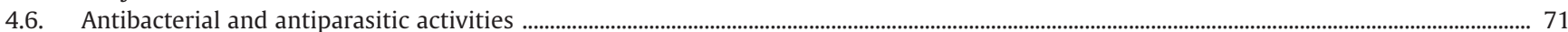

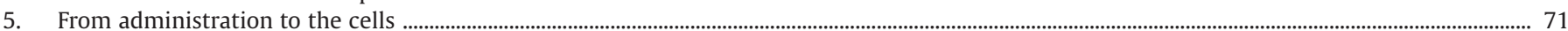

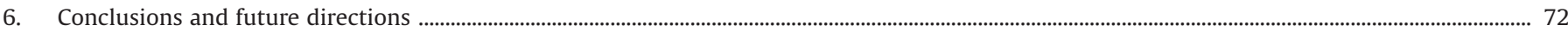

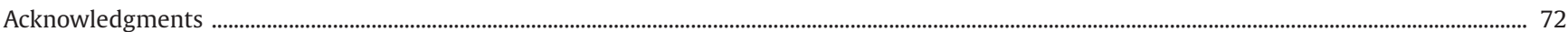

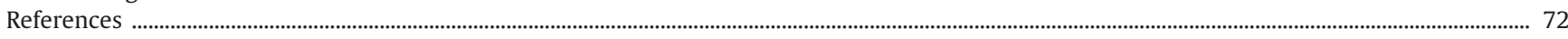

Abbreviation: ALA, $\alpha$-linolenic acid; LA, linoleic acid; EPA, eicosapentaenoic acid; DHA, docosahexaenoic acid; AR, 5-alkenylresorcinol; ACP, acylphlorogucinol; n-3 PUFA, omega-3-polyunsaturated fatty acid; PC, phosphatidylcholine.

* Corresponding author.

E-mail addresses: celine.crauste@univ-montp1.fr (C. Crauste), melissa.rosell@etud.univ-montp2.fr (M. Rosell), thierry.durand@univ-montp1.fr (T. Durand), jvercauteren@ univ-montp1.fr (J. Vercauteren). 


\section{Introduction}

Health benefits of polyunsaturated fatty acids of the omega-3 family have been largely reported in the last decades [1,2]. The most common ones are $\alpha$-linolenic acid (C18:3, ALA), eicosapentaenoic acid (C20:5, EPA) and docosahexaenoic acid (C22:6, DHA). They are reported as "essential fatty acids", seem to be involved in the reduction of inflammation and may help lower risk of chronic diseases such as heart disease, cancer, and arthritis. As they are highly concentrated in the brain, they are also implicated in cognitive and behavioral functions [3]. Several omega-3-polyunsaturated fatty acid ( $n-3$ PUFA) conjugates have been developed in recent literature to improve the efficiency of active molecules. Among them, this review will focus especially on PUFA-Phenol conjugates, including inter alia, flavonoid, catechol, phloroglucinol derivatives, already known for their therapeutic applications (anti-oxidative, anti-inflammatory, anticancer activities ...) [4], as well as natural omega-3 lipophenols.

The rational to design lipophenol derivatives depends either on the initial phenolic drug or on the targeted pathology: linkage of highly hydrophilic drugs to n-3 PUFA may help to increase lipophilicity, cell penetration and bioavailability of specific polar phenolic drugs. On the contrary, conjugation with PUFA would be interesting to reach appropriate solubility of hydrophobic drugs, by facilitating its binding to human serum albumin (HSA) [5,6]. In some cases, PUFA conjugates have been investigated to target specific tissues, either ones rich in n-3 PUFA such as retina or brain (high content in DHA and EPA) $[3,7]$, or tumor tissues in which PUFA uptake is particularly high. On one side, since PUFAs are prime targets for oxidation (due to numerous bis-allylic positions) [8], linkage with antioxidant such as phenolic compounds would also help to limit auto-oxidation, to prevent the resulting harmful effects of lipid oxidation and to preserve health benefits of PUFA. On the other side, esterification of phenolic drugs by PUFA is a good way to mask their hydroxyl polar functions and thus, to reduce their biotransformation or the pace of oxidative degradation. In addition, conjugation with a PUFA part may contribute to increase antioxidant properties of phenolic compounds in lipophilic media. Depending on the pathology studied, synergism effect between the phenolic and the PUFA parts could be expected. In those cases PUFA would be able to enhance the efficacy of the phenolic drug, not only by the release of the drug but by the combined functionality of both moieties of the conjugate (including their metabolites).

For all those reasons several research teams worked on the synthesis and the evaluation of a wide range of lipophenols, however, natural sources offer also the possibility to access lipophenol structures. As an example, several lipophenols bearing a n-3 PUFA part and a phloroglucinol moiety have been identified, mainly in vegetable sources [9]. Interest in natural n-3 lipophenols resides in their diverse biological activities.

As an illustration, we describe herein the main synthetic strategies to access n-3 lipophenols, the source and/or the total synthesis of natural n-3 lipophenolic derivatives, and we will discuss the current and potential therapeutic applications of the resulting compounds presented in the literature. Even though other n-3 PUFA conjugates bearing phenolic residues have been described, this review will focus specifically on bioactive compounds in which the phenolic or polyphenolic moiety plays a major role in the biological properties of the molecule.

\section{The chemical or enzymatic pathway to access n-3 lipophenols}

Introduction of PUFA on phenolic cores can be performed chemically, enzymatically, or chemo enzymatically, most often through esterification/acylation of the phenolic-OH with fatty acids. Fig. 1 presents phenolic molecules that have been transformed into li- pophilic derivatives using n-3 PUFAs, with position of the reported acylation in red/pink color.

\subsection{Enzymatic synthesis}

The synthesis of n-3 PUFA-phenols depends on the structure of the phenolic part. Indeed, different types of bioactive phenols have been linked to ALA, EPA or DHA. Among them, are reported polyphenolic compounds belonging to the flavonoids family such as rutin $\mathbf{5}$, phloridzin $\mathbf{6}$, isoquercitrin $\mathbf{7}$, naringin $\mathbf{4}$, quercetin 3 or epigallocatechins 1-2 (Fig. 1). The enzymatic way, involving lipases, most usually novozyme 435 (commercially immobilized lipase from Candica antarctica - CALB), is always preferred to the chemical one to introduce PUFA on heterosidic flavonoids. Its high regioselectivity allows introduction of only one fatty acid (FA) residue on the sugar part, and mild reaction conditions avoid substrate alteration. The most studied flavonoid for this purpose was rutin (5).

Enzymatic esterification using CALB is usually performed in acetone [10-12], 2-methyl-2-butanol [13,14] or in a mixture of both solvents [15], which were selected for their abilities to solubilize both the reactant and the final lipophenol, providing excellent activity and stability of the lipase. The lipase allows the introduction of ALA, EPA or DHA specifically at the 4"'-hydroxyl group of the rhamnosyl moiety. Mbatia et al. [10] performed the reaction using a mixture of PUFAs enriched in ALA, EPA and DHA, in proportion phenol/FA $1 / 4$ at $50{ }^{\circ} \mathrm{C}$ during $96 \mathrm{~h}$. They reported $30 \%$ yield of the 3 lipophenols (5) without purification. Using similar protocol with pure ALA (phenol/FA $1 / 5,50{ }^{\circ} \mathrm{C}, 96 \mathrm{~h}$ ), Mellou et al. [11] observed up to $68 \%$ of esterification (measured by HPLC) while Viscupicova et al. $[13,14]$ obtained around $30 \%$ of conversion using the same PUFA (phenol/FA: $1 / 5,60^{\circ} \mathrm{C}, 168 \mathrm{~h}$ ). Those works pointed out that the yields of enzymatic rutin esterification, inversely correlates the chain length of fatty acid (with C4-C12 fatty acids, yield $>50 \%$ ), probably due to steric hindrance/constraints in the active site of the CALB. It has also been reported that the presence of double bonds could negatively influence the lipase specificity to a large extent. However this was not clearly demonstrated with rutin.

More recently Zheng et al. [15], introduced ultrasound activation to link ALA to rutin (5) and naringin (4) in the presence of CALB (wrong structure of naringin is reported by the authors). Microtip probe ultrasonic pretreatment to esterification of flavonoids (frequency $25 \mathrm{KHz}$, power 150-200 W), allowed to use lower PUFA's equivalents and reduced reaction time (48-72 h instead of 72$96 \mathrm{~h}$ ), compared to stirring experiments to reach up to $80 \%$ of conversion without damaging the lipase. Ziaullah et al. [12] were the only ones to perform phloridzin acylation at the 6 " position of the glucose, with each of the three PUFAs ALA, EPA and DHA, using the stirring process (acetone, $45^{\circ}-50{ }^{\circ} \mathrm{C}, 12-24 \mathrm{~h}$ ) and obtained respectively 94,85 and $82 \%$ yields after purification of phloridzinALA, -EPA and -DHA 6. The same work on isoquercitrin (7) led to the acylation of the $6^{\prime \prime}-\mathrm{OH}$ position of the sugar moiety with a complete regioselectivity and 91,81 and $81 \%$ yield, respectively. In addition to the presence of flame dried molecular sieves to remove any in situ generated water in the reaction mixture, they focused on the need to dry the enzyme over $\mathrm{P}_{2} \mathrm{O}_{5}$ for $20 \mathrm{~h}$ before the reaction and to maintain extra dry condition so as to limit hydrolysis and drag the reaction forward.

Lipase-catalyzed esterification and transesterification were used to produce lipophenol structures having a catechol part like vanillyl alcohol, dihydrocaffeic acid or hydroxytyrosol. Using the specificity of CALB to acylate primary hydroxyl groups compared to secondary hydroxyl ones, MBatia et al. [10] reported, as for rutin but with an increased yield (60\%), the synthesis of a mixture of ALA, EPA and DHA vanillyl esters 10, using CALB in acetone. Additionally, EPA and DHA were introduced in the olive oil hydroxytyrosol (13) and in analogue structures through transesterification, cata- 
<smiles>[R]Oc1cc(C2Oc3cc(O)cc(O)c3C[C@H]2OC(=O)c2cc([R2])c(O)c([R])c2)cc([R])c1O</smiles><smiles>[R]OC1Cc2c(O)cc(O)cc2OC1c1cc(O)c(O)c(O)c1</smiles><smiles>[R]Oc1ccc(-c2oc3cc([R])cc(O[R])c3c(=O)c2O[R])cc1O[R]</smiles>

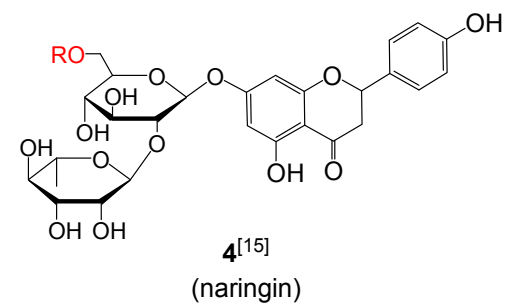

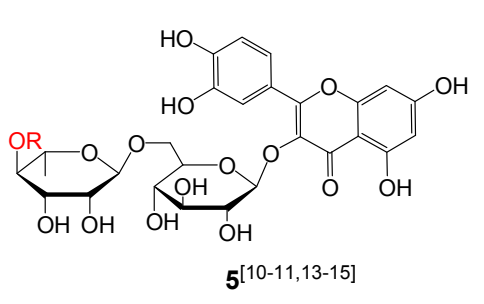

(rutin)<smiles>[R]CC1C=C(O)C(C(=O)CCc2ccc(O)cc2)C(OC2C(O)C(O)C(O)C(O)C2O)O1</smiles>

(phloridzin)

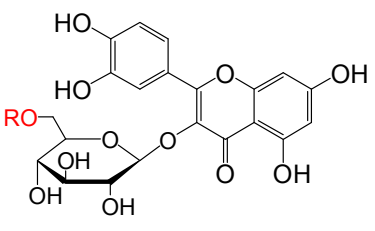

$7^{[12]}$

(isoquercitrin)<smiles>[R]OCc1ccc(O)c(OC)c1</smiles>

(vanillyl alcohol)<smiles>[R]NCc1ccc(O)c(OC)c1</smiles>

$11^{[26,29,67]}$

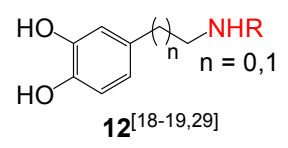

(dopamine and analogues)<smiles>[R]OC=Cc1ccc(O)c(O)c1</smiles>

$13^{[16]}$

(hydroxytyrosol and analogues)<smiles>[R]C1NCCc2cc(OC)c(OC)cc21</smiles>

$8^{[38]}$

(tetrahydroisoquinoline)<smiles>[R]CC([R])OC(=O)CCc1ccc(O)c(O)c1</smiles>

(dihydrocaffeic acid - DHCA)<smiles>[R]Oc1cc(O)cc(OP)c1</smiles>

$15^{[37]}$ (phloroglucinol)<smiles>[R]N[C@@H](CO)Cc1ccc(O)cc1</smiles>

(Farinosone $\mathrm{C}$ analogue)

(Phenolic parent in brackets)<smiles>[R]CCCC(=O)Oc1cc(O)cc(O)c1</smiles>

$16^{[37]}$

(adipyl phloroglucinol)<smiles>[R]Oc1cccc2c1C(=O)C=CC2=O</smiles>

(juglone)<smiles>[R]Oc1cc(O)cc(/C=C/c2ccc(O)cc2)c1</smiles>

(b)

4'-PUFA:17a ${ }^{[22,37]}$

3-DHA: 17b (resveratrol)<smiles>[R]Nc1c(OC)cc(OC)cc1OC</smiles>

$18^{[21]}$ (trimethoxy anilide)<smiles>[R]Oc1c(C(C)C)cccc1C(C)C</smiles>

$19^{[24,66]}$ (diisopropylphenol)

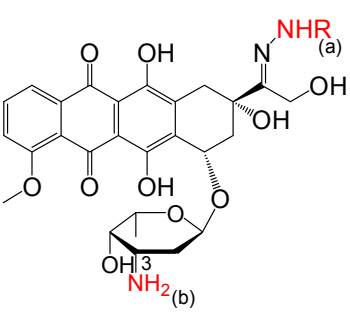

Dox-hyd-PUFA: 24a Dox-3-ami-PUFA: 24b (doxorubicin) $^{[25,63-65]}$<smiles>[R]OC(CC=C(C)C)C1=CC(=O)c2c(O)ccc(O)c2C1=O</smiles>

(shikonin)

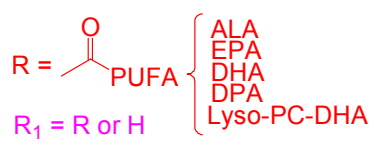<smiles>[R]Oc1c(OC)cc([C@H]2c3cc4c(cc3CC3COC(=O)[C@@H]32)OCO4)cc1OC</smiles>

$23^{[27]}$

DDPT

Fig. 1. Chemical structures of published synthetic n-3 PUFA lipophenols.

lyzed by CALB under stirring and vacuum $\left(5-10 \mathrm{mmHg}, 37^{\circ} \mathrm{C}\right.$, 4-16 h, 29-97\%) [16]. In this work, important decreased yields were observed, going from EPA and DHA ethyl esters to saturated ethyl palmitate and stearate esters. Weak conversions were explained by the partial hydrolysis of the PUFA ethyl esters during the reaction. Finally, CALB was used to investigate the lipase transesterification reaction of dihydrocaffeic acid (DHCA) with flaxseed oil (rich in ALA and other C18 fatty acids glycerides), in order to obtain phenolic mono or diacyl glycerol enriched in ALA (14). The high specificity and stereoselectivity of the enzyme towards C18:1 n-9 and C18:2 $\mathrm{n}-6$ for transesterification reaction, led to an increased proportion of ALA in the phenolic diacyl glycerol structure [17].

\subsection{Chemical synthesis}

The introduction of a PUFA moiety onto chemical structures having a single free phenolic function (juglone $\mathbf{2 1}$, propofol 19, podophyllotoxin derivatives 23), or one amino or aliphatic-alcohol group, with higher nucleophilicity than the phenolic one (dopamine and analogues $\mathbf{1 2}$, trimethoxy anilide $\mathbf{1 8}$, farinosone C $\mathbf{2 0}$, shikonin $\mathbf{2 2}$ ), was performed either by the well-established esterification procedure using either the proper preformed mixed anhydrides [18,19] or acyl chlorides [20-22] of the PUFA, or a classical coupling reagent, such as, DCC/DMAP [23-27], pentafluorophenol/TEA [28], TBTU/ TEA [29] or TCTU/TEA [30]. Whatever the used procedure and reagents, moderate to good yields were obtained.

For more complex polyphenolic structures like epigallocatechine3-O-gallate (EGCG) $\mathbf{1}$ [31-33], epigallocatechin (EGC) 2 [34,35], quercetin 3 [36], phloroglucinol 15 or resveratrol 17 [37], two different strategies are used: with or without phenolic protection. On the one hand, uncontrolled acylation leading to the introduction of the FAs on several phenolic functions have been reported for quercetin and EGCG. Penta, tetra and tri-esters of quercetin (3) were obtained using acyl chloride of ALA [36]. Unsaturated acyl chlorides/ phenols molar ratio modulation allowed Mainini et al. to obtain preferentially pentaesters (74\%) when using phenolic/FA in a 1 to 
$E G C-A L A$

Hiipakka et al. pathway ${ }^{[34]}$

$$
\text { Lin et al. pathway }{ }^{[35]}
$$

1) $\mathrm{TBDMSCl}$

Imidazole

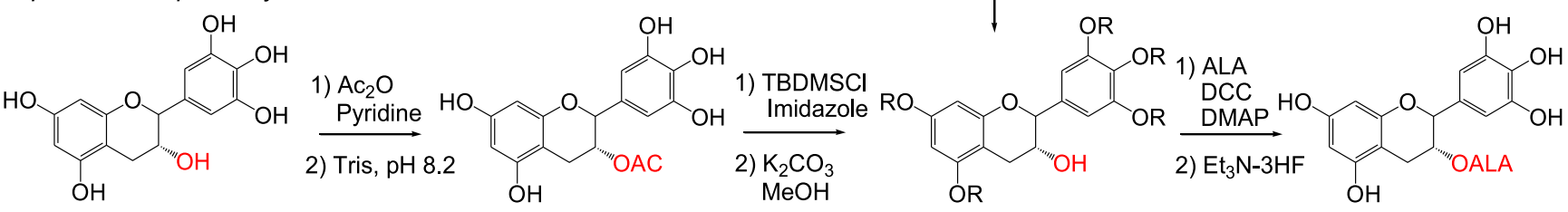

alkyl-phloroglucinol-PUFA ${ }^{[37]}$

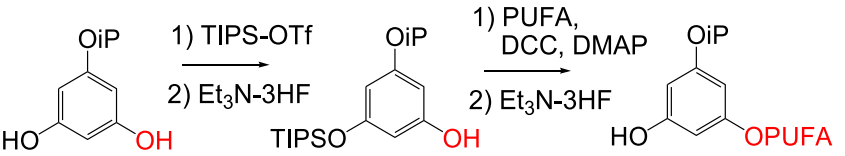

15

PC-DHA-phloroglucino/ ${ }^{[37]}$

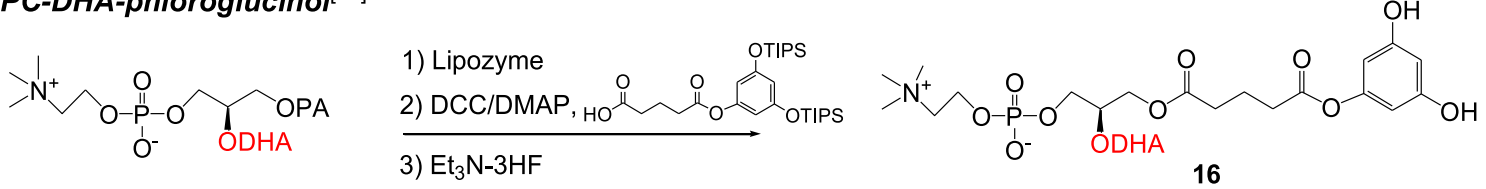

resveratrol-PUFA ${ }^{[37]}$<smiles>Oc1ccc(C=Cc2cc(O)cc(O)c2)cc1</smiles>

\author{
1) CalB, \\ vinyl acetate \\ 2) $\overrightarrow{\text { TIPS-OTf }}$
}<smiles>C/C=C(/C)OC(C)=O</smiles><smiles>CN(C)CC[SnH3]</smiles>
1) PUFA, DCC, DMAP 2) $\mathrm{Et}_{3} \mathrm{~N}-3 \mathrm{HF}$

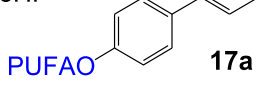

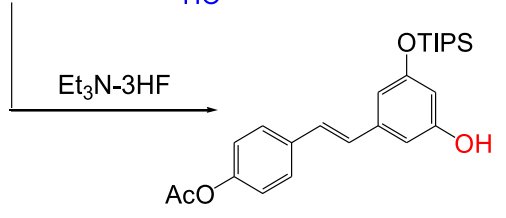

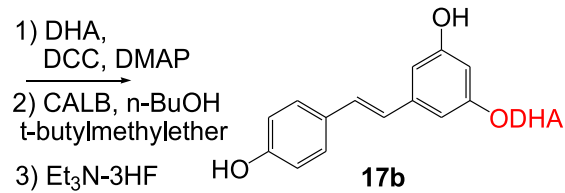

\section{doxorubicine-PUFA ${ }^{[63-65]}$}

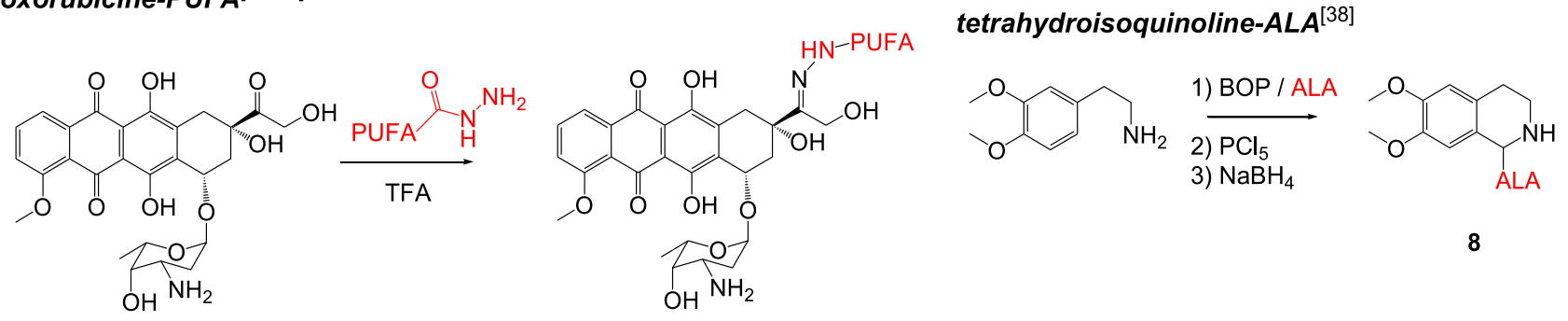

Scheme 1. Examples of n-3 PUFA lipophenol chemical synthesis

10 ratio or a mixture of tetra and triesters ( 45 and $15 \%$, respectively) at $1 / 4$ ratio. Zhong et al. [31-33] synthesized preferentially EGCG$3^{\prime}, 5^{\prime}, 3^{\prime \prime}, 5^{\prime \prime}-\mathrm{O}$ - tetraesters of DHA and EPA 1, using acyl chloride reagents.

On the other hand, chemical strategies, involving protection and deprotection steps, were developed to access to (regio)selective mono PUFA conjugates of phloroglucinol 15, resveratrol 17 [37] or EGC 2 [34,35] (Scheme 1).

Two strategies were reported for the synthesis of 3-O-ALAEGC 2. Starting from hexa-acetylated EGC, the first one [34] used the selective deprotection of phenolic acetate in the presence of Tris buffer to obtain 3-O-monoacetate derivative. Silylation of the phenolic hydroxyls, deacetylation and ALA coupling afforded the desired lipophenol after mild "HF deprotection". Lin et al. [35] chose EGCG as starting material in which the gallate group plays the role of a protecting group of the 3-OH position, easily deprotected by $\mathrm{LiAlH}_{4}$ reduction. Despite a close reactivity of the symmetrical phenolic hydroxyls of the phloroglucinol (15), Crauste et al. [37] managed to selectively remove one out of the three TIPS groups using triethylamine-3HF, thus allowing monoacylation by DHA in the presence of DCC/DMAP. In the same work, a chemical-enzymatic pathway was used to couple a phenolic derivative to sn1-lyso-PC-DHA. 
Sn1-Lyso-phosphatidylcholine-DHA was itself obtained through a selective enzymatic hydrolysis at the $s n 1$ position, using liposyme immobilized from Mucor miehei, of a commercially available PC. Desired lipophenol 16 was isolated by coupling of adipoyl-silylated phloroglucinol, followed by HF deprotection. Finally, resveratrolDHA acylated either at the $4^{\prime}$ position 17a or at the 3 position 17b (Crauste et al. unpublished results) were obtained using CALB as selective enzyme for acylation and deprotection of the $4^{\prime}$ position of resveratrol, and $\mathrm{Et}_{3} \mathrm{~N}-\mathrm{HF}$ to perform the mono deprotection of TIPS groups on A ring of resveratrol.

At the difference with ester or amide linkages between the phenolic compound and the PUFA part, non hydrolysable bounds have been obtained [38] by synthesizing a tetrahydroisoquinoline derivative $\mathbf{8}$ with ALA side chain using a Bischler-Napieralski cyclization reaction. Original anti-cancer DHA-doxorubicin conjugate (DOXhyd-DHA 24a) was obtained using a cleavable hydrazone linker [39]. Since $\mathrm{pH}$ in tumor cells is lower than in healthy tissue, the hydrazone bond, stable at pH 7.4, is rapidly cleaved at lower $\mathrm{pH}$ in cancerous cells. DOX-hyd-DHA was synthesized by reaction of hydrazinamide-DHA (activated by Boc-hydrazine) on doxorubicin.

\section{Natural n-3 PUFA lipophenols: sources and total synthesis}

\subsection{Natural sources}

In addition to synthetic derivatives, several lipophenols have been isolated from natural sources. They can be related to analogues of n-3 PUFA lipophenols, since they are linked to n-3 unsaturated carbon chain (C11-C21) with skipped Z-double bonds separated by bis-allylic positions and starting from the $\mathrm{C} 3$ of the alkyl chain. At the difference with synthetic n-3 PUFA lipophenols, the presence of an alkenyl part directly linked to the aromatic cycle, without ester function, is widely represented (Fig. 2).

Usually, the crude extract rich in n-3 PUFA lipophenols is obtained through extraction process (using water, ethanol, ethyl acetate, methanol, diethyl ether, methylene chloride, chloroform, petroleum ether) from the natural sources. Purification by chromatographic methods (typically, silica gel column) is performed to lead to isolated compounds. The percentage values given in the following section are calculated as a fraction of the weight of isolated lipophenol related to the weight of the extract. In some cases percentage refers to dried or fresh matter and is mentioned with (\% from DM or FM).

Most of the natural n-3 PUFA lipophenols (Fig. 2) have been isolated from vegetables or animals from marine origin. Hemiketal spiralisone $\mathbf{2 5}$ was isolated from Zonaria spiralis (5.3\%) [40], a marine brown algae, together with the chromone $\mathbf{2 6}$ (1.6\%), which was also found in several other brown algae of the Zonaria genus, like Zonaria tournefortii [41]. Chromone $\mathbf{2 6}$ is presented to be a possible artifact of 25, by dehydration, favored by mildly acidic conditions. Z. tournefortii is also a source of acylphloroglucinol (ACP) derivatives 37 [42] (8\% and 0.3\% from DM), in addition to other brown marine algae like Zonaria diesingiana (5.3\%) or Zonaria farlowii (11\% and $0.13 \%$ from fresh alga) [9]. The later also contains the specific ACP derivative 38 (2.2\%) [9]. Other algae, such as Cystophora torulosa was shown to contain ACP $\mathbf{4 0}$ (0.19\%) and 5-alkenylresorcinol (AR) 30 derivatives [43] (15\% in mixture with other alkyl resorcinols), Chorthippus scalaris to contain $\mathbf{4 0}$ and $\mathbf{3 9}$, while from Chrysanthemoides monilifera and Cordyline congesta $\mathbf{3 9}$ was isolated $(<0.07 \%$ from DM) [44]. In addition to marine vegetables, some animal marine sources have been found to produce $n-3$ PUFA lipophenols. The 5-alkenylresorcinols (AR) 29, 30, 31, 35 and $\mathbf{3 6}$ have been isolated from the sponge Haliclona sp (between 0.22 and $0.67 \%$ ) [45], while tyramine derivative $\mathbf{2 8}$ can be found in octocoral Muricea austera from the Pacific coast of Panama [46].

Apart from marine sources, natural n-3 PUFA phenols also have been identified in different and various plant species. The macamide 27 is present in Peruvian plant Lepidium meyenii (Maca), however its proportion in Maca extract is very low (less than $0.01 \%$ from DM) [47]. Leaves and stems of Philodendron scadens subsp. oxycardium contain the anacardic acid derivative $\mathbf{4 2}(0.016 \%$ of FM) and the AR $29(0.005 \%$ from FM), which is the major allergen compound and a weapon defense of the plant [48]. The AR $\mathbf{2 9}$ has various origins and can also be isolated from liverwort Omphalantus filiformis [49] (mainly in the cuticle) and leaves of Stylogyne turbacensis [50]. Anacardic acid derivative $\mathbf{4 2}$ is also present in various other sources and has been isolated from leaves of Anacardium spondias [39], and leaves and stems of Spondias mombin [51]. The AR 32 comes from ground aerial part of the tree Lithraea molleoides (0.16\%) [52], while AR 34 was extracted from wheat bran oil ( $0.007 \%$ from the oil) [53]<smiles>[R]C1(O)CC(=O)c2c(O)cc(O)cc2O1</smiles>

hemiketal spiralisone $\mathrm{R}=\mathrm{Alk}_{7} \mathbf{2 5}^{[40]}$<smiles>[R]c1cc(=O)c2c(O)cc(O)cc2o1</smiles>

$\mathrm{R}=\mathrm{Alk}_{7} \mathbf{2 6}^{[40-41,57,62]}$<smiles>[R]C(=O)NCc1cccc(OC)c1</smiles>

$\mathrm{R}=\mathrm{Alk}_{3} 27^{[47,68-70]}$

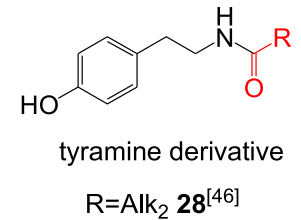

$\mathrm{R}=\mathrm{Alk}_{2} \mathbf{2 8}^{[46]}$<smiles>[R]C(=O)OCC=Cc1ccc(O)cc1</smiles>

Z-p-Coumaryl linolenate $\mathrm{R}=\mathrm{Alk}_{3}$ 41 $^{[54]}$

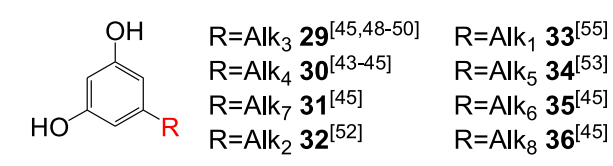

5-Alkenylresorcinol derivative (ARs)

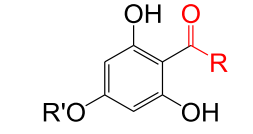

Acylphloroglucinol (ACP)

$\mathrm{R}=\mathrm{Alk} \mathrm{k}_{7} ; \mathrm{R}^{\prime}=\mathrm{H} \quad \mathbf{3 7 ^ { [ 9 , 4 2 ] }}$

$\mathrm{R}=\mathrm{Alk}_{7} ; \mathrm{R}^{\prime}=\mathrm{CH}_{3} \quad 3^{\left[{ }^{[9]}\right.}$

$\mathrm{R}=\mathrm{Alk}_{4} ; \mathrm{R}^{\prime}=\mathrm{H} \quad 39^{[44]}$

$\mathrm{R}=\mathrm{Alk}_{4} ; \mathrm{R}^{\prime}=\mathrm{CH}_{3} \quad 40^{[43-44]}$ derivatives<smiles>[R]c1cccc(O)c1C(=O)O</smiles>

Anacardic acid derivative $\mathrm{R}=\mathrm{Alk}_{3}$ 42 $^{[39,48,51,71]}$
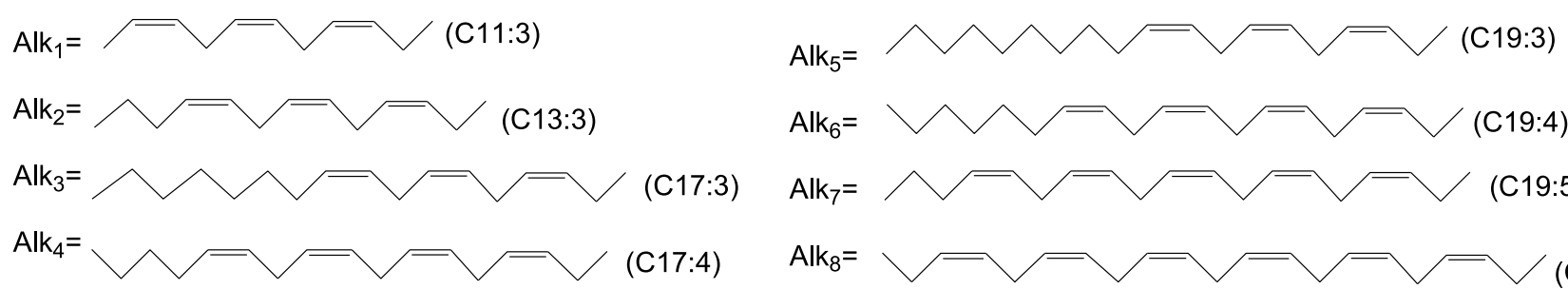

$\mathrm{Alk}_{8}=$

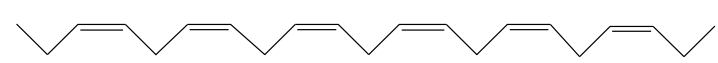

Fig. 2. Chemical structures of natural n-3 PUFA lipophenols. 
<smiles>CC/C=C\C/C=C\C/C=C\C/C=C\CCCC(=O)OCC</smiles>

ethyl ester of eicosapentaenoic acid<smiles>CC/C=C\C/C=C\C/C=C\C/C=C\CCCc1cc(=O)c2c(O)cc(O)cc2o1</smiles>

1) DIBAL-H, $97 \%$

2) $\mathrm{LDA}, \mathrm{TMSCHN}_{2}, 58 \%$

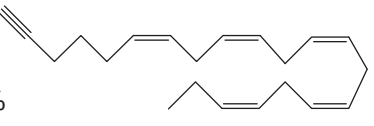

$\sim$

$60 \%$

1) $\mathrm{MnO}_{2}, \mathrm{CH}_{2} \mathrm{Cl}_{2}, 88 \%$

2) $\mathrm{HCl}, \mathrm{EtOH}$

3) $\mathrm{K}_{2} \mathrm{CO}_{3}$, acetone, $49 \%$

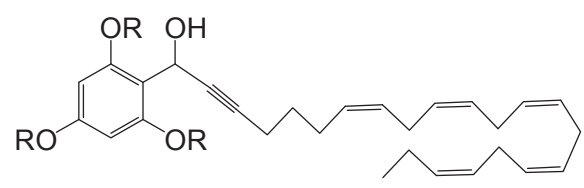

Scheme 2. Total synthesis of chromone 26 [57].

and traces of $Z-p-O$-coumaryl linolenate $\mathbf{4 1}$ has been observed in the peel of cv. Annurca Apple fruits [54].

Finally, AR 33 has been isolated from a microorganism, heterotrich ciliate Climacostomum virens. This compound can potentially be a defense toxin against the predatory ciliate Dileptus margaritifer [55].

Globally, the richest sources of lipophenol derivatives are from marine origin, especially algae: $1.6 \%$ to $11 \%$ (weight \% extract) for the genus Zonaria, and up to $15 \%$ (weight \% extract) of some alk(en)ylresorcinols for the genus Cystophora. The marine sponge Haliclona sp. contains fives different AR in amounts ranging from $0.22 \%$ to $0.58 \%$ (weight \% extract). In addition, most of the natural $\mathrm{n}-3$ lipophenols derivatives are also found in plants, mainly in the leaves and stems.

\subsection{Biosynthesis and total synthesis}

Zhang et al. [40] proposed a biosynthetic pathway, starting from the monomeric phloroglucinol to access the racemic spiralisone $\mathbf{2 5}$ and chromone derivative $\mathbf{2 6}$, found in various sources of algae: after formation of an acylphloroglucinol intermediate in the presence of acetyl-CoA, elongation via a Claisen condensation on an activated fatty acid would lead to the incorporation of the polyunsaturated part. The resulting acylphloroglucinol $\beta$-diketone would undergo intramolecular cyclization to afford the spiralisone derivative, then the chromone upon dehydration. While following the same reflection, El Hattab et al. [56], supposed that Claisen condensation could be performed on a pentaketide precursor to form directly the acylphloroglucinol $\beta$-diketone.
From the chemical point of view, the first total synthesis of $\mathbf{2 6}$ was reported by Anwar et al. [57] (Scheme 2), in six steps starting from an ester of EPA, in a 14\% overall yield. The ethyl ester of EPA is first transformed into a terminal alkyne through its hemireduction to the aldehyde, followed by a Colvin rearrangement. This alkyne is then coupled with 2,4,6-tris(methoxymethoxy)benzaldehyde using $n$-BuLi. After oxidation of the obtained secondary alcohol, and deprotection of the phloroglucinol moiety, intramolecular Michael addition under basic conditions, afforded the desired chromone $\mathbf{2 6}$.

AR and ACP represent the largest family of natural lipophenols. In plant, their biosynthesis is believed to follow the polyketide pathway (Scheme 3): in a few words, a fatty acylCoA starter undergoes three condensation reactions with malonylCoA leading to a tetraketide intermediate [56,58], which can undergo two ring formation mechanisms: an aldol condensation (followed by an easy loss of carboxyl) would conduct to AR structures, while Claisen condensation allows to the formation of ACP. However, hypothesis of polyunsaturated long-chain AR biosynthesis has also been proposed for AR compound 33, in which the polyunsaturated part would be formed after cyclization and decarboxylation of a C18-polyketide [55,59] (Scheme 3).

\section{4. n-3 PUFA lipophenol activities}

\subsection{Antioxidant and anticarbonyl stress activity}

Most of the combinations of n-3 PUFA with natural antioxidants such as flavonoids, have been proposed to increase their
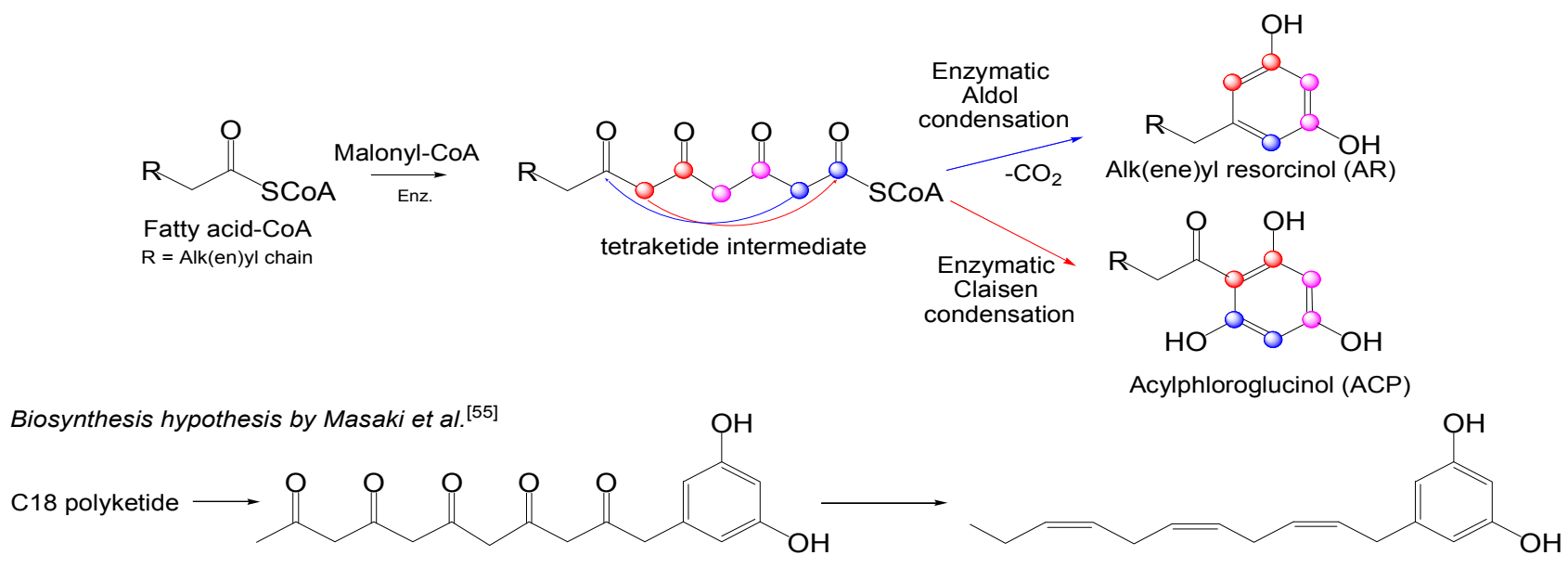
lipophilicity for two main purposes: (1) to increase their preservative effects against oxidation [10,14] of lipophilic food matrices; (2) to circumvent their use limitation, due to their low skin/cell permeability, solubility or bioavailability in the dermocosmetic, nutraceutic or therapeutic applications, benefitting additional health promoting effects related to the n-3 PUFA moiety.

To date, many in-vitro tests (test-tube or in cell assays) are available to detect, quantify and compare antioxidant capacity and ability of chemicals to protect a substrate against oxidation, but unfortunately none of them are universal. When comparing antioxidant results, it should always be kept in mind that the result of those tests will depend not only on the direct activity of phenolic compounds, but also on other parameters, such as their own solubility, as well as the one of the substrate (to be protected from oxidation) and on the lipidic and/or aqueous medium in which the assays are performed. Using two different methods, discrepancies between the found activities are unavoidable. Different experimental conditions in terms of solubility, of accessibility of the oxidant to the oxidation site, of the location and/or of the distribution of the antioxidant, will make the antioxidant potencies difficult to compare $[60,61]$. Efficacy of antioxidant linked to PUFA compared to the initial phenol is mainly reported using homogeneous DPPH radicalscavenging activity assay, sometimes ABTS, FRAP or ORAC assays. In the case of protection of lipophilic food matrix, $\beta$-carotene linoleate method, rancimat test, or thiobarbituric assay (compared to $\alpha$-tocopherol or butylated hydroxytoluene (BHT) activity) have been employed. It was surprising to observe, that, to the best of our knowledge, most of the evaluation of antioxidant activity of n-3 PUFA phenol were performed in cell free assay. Unfortunately, such assays do not take into account the enzymatic cleavage of the ester bounds, which, in some lipophenolic structures, could free the lipid part and unmask the active phenolic functions.

All n-3 PUFA-phenol esters tested in literature showed radical scavenging activity in the DPPH radical assay $[10,12,14,17,33,36]$. It is worthy of note that even though the structures contain an easily oxidizable PUFA, the lipidic part appears to be protected from oxidation by conjugation with phenolic residue. To date there is not a clear correlation between the introduction of the lipid part and the increase or the decrease in the radical scavenging capacity of the phenolic derivative. There is an important relationship between the hydrophobic nature of the new lipophenol and its activity, which will depend on the nature of both the lipid and the phenolic part and also on the binding position.

According to Zhong et al. [33] EPA and DHA tetra esters of EGCG $\left(3^{\prime}, 5^{\prime}, 3^{\prime \prime}, 5^{\prime \prime} \mathrm{O}\right.$ esters, 1$)$ exhibited both a greater antioxidant activity in scavenging $\mathrm{DPPH}^{\circ}$ (determined by electron paramagnetic resonance-EPR) than EGCG itself. In this study, Zhong et al. suggest that the lipophenol with enhanced lipophilicity may have greater accessibility to the lipophilic DPPH radical than the hydrophilic flavonoid. In addition, it is proposed by the authors that acylation on $3^{\prime}, 5^{\prime}, 3^{\prime \prime}$ and $5^{\prime \prime}$ positions, may reduce electron density of the $\mathrm{O}-\mathrm{H}$ bound at position $4^{\prime}$ and $4^{\prime \prime}$ (due to the electron withdrawing property of both acyl groups in ortho position), thus enhancing the ability to scavenge radical in these position. On the contrary, quercetin (penta, tetra, and tri) ALA esters 3 display a lower antioxidant activity with respect to free quercetin in both $\mathrm{DPPH}\left(\mathrm{IC}_{50}: 4.72 \mathrm{vs}\right.$ triesters: $107.26 \mu \mathrm{g} \mathrm{ml}^{-1}$ ) and ABTS assay (TEAC: $1930 v s$ triesters $1.33 \mathrm{mg} \mathrm{g}^{-1}$ ) [36]. Triesters, in which the $\mathrm{OH}$ at positions 5 and 3 are free, display a higher activity than pentaesters having only $5-\mathrm{OH}$ free. This result highlighted the relevance of a free $\mathrm{OH}$ at the 3 position for the design of lipophenolic quercetin antioxidant, compared to free $\mathrm{OH}$ at the 5 position able to create intramolecular $\mathrm{H}$-bonding with the carbonyl function. It is worthy of note that the antioxidant activity of PUFA-quercetin increases with the number of unsaturations in the FA. Similarly, when exposed to $\mathrm{DPPH}^{\circ}$, free DHCA manifested higher radical scavenging ability (62\%), than its lipid (ALA- acyl glycerol) conjugate (compound 14, only 19\%) [17]. According to Sabally team, this huge drop in its radical scavenging ability could be attributed to limitation in conformational changes in the lipophenol derivative. Mbatia et al. [10] reported the same observation with ALA, EPA and DHA vanillyl esters 10, whose the radical scavenging activities were lower than for vanillyl alcohol itself. A great increase in hydrophobicity may have resulted in decreased vanillyl esters solubility in the tests medium. Again, with the rutin 5, phloridzin 6 and isoquercitrin 7 PUFA-derivatives, and even though the omega-3 acids were linked to the sugar moieties (which is not considered to be the crucial part for a molecule to display such a property), only the PUFA-rutin esters 5 had the same [10] or just a weaker [14] capacity to scavenge radicals than the free rutin, in the DPPH assay. Despite a substantial antioxidant activity in FRAP and DPPH assays, phloridzin 6 and isoquercitrin 7 esters (ALA, EPA, DHA) have a lower free radical scavenging activity than the parent compounds. This effect may be attributed to the steric hindrance of PUFA since the number of double bonds of the FA seems to influence the antioxidant capacity. However, the correlation is not working in the same way, depending on the antioxidant assay performed.

When protection of acyl glycerol enriched in PUFA from oxidation (TBARS assay) is tested in a lipophilic medium, rutin and vanillylPUFA esters $\mathbf{5}$ and $\mathbf{1 0}$ showed lower antioxidant activity than BHT but were stronger than the lipophilic $\alpha$-tocopherol, in oil emulsion [10]. However, none of them was better antioxidant than any of these two references in fish oil system. In contrast, rutin-ALA ester 5 exhibited the best inhibition of lipid peroxidation in $\beta$-carotene linoleate system comparable to that of BHT [14]. Inhibition was higher than rutin and as active as rutin-palmitate and stearate. Those results reported by Viskupicova et al. also clearly demonstrate that hydrophobicity has an impact on the antioxidant capacity of rutin derivatives in lipophilic food systems (sun flower oil), since better protections were observed using long-chain FA (C16-C18) compared to shorter ones (C4-C10). In this case, the numbers of double bond in C18 FA did not influence the activity. Natural Z-p-coumaryl linolenate $\mathbf{4 1}$ showed the same ability (50\%) to inhibit the production of peroxides in the methyl linoleate autoxidation assay as its linoleic analogue [54].

Oxidative and carbonyl stress are closely related since most of toxic carbonyl stressors may come from lipid peroxidation end products. Recently, Crauste et al. [37] developed lipophenol derivatives in order to reduce oxidative and carbonyl stress in retina pathologies. PUFA such as DHA was selected because of its high proportion in retina cell membranes, suggesting a possible vectorization to target retina tissues. Isopropyl-phloroglucinol-DHA conjugate $\mathbf{1 5}$ was able to protect ARPE-19 and primary cells of the retinal pigment epithelium (RPE) against both $\mathrm{H}_{2} \mathrm{O}_{2}$ and trans-retinal stress (Crauste et al. to be published and [37]). In ARPE-19 cells assay, DHA lipophenolic conjugate allowed to increase cell survival up to $40 \%$ in presence of a toxic concentration of trans-retinal, while free DHA and isopropyl-phloroglucinol mixture was inactive. Protection against trans-retinal toxicity could be attributed to the trapping of the toxic aldehyde (carbonyl scavenger) leading to a chromene derivative. Among several PUFA conjugates ALA and DHA phloroglucinol 15 presented higher in vitro protection against carbonyl stress, and saturated C22 fatty acid conjugation led to a weak activity (Crauste et al. unpublished result).

Interestingly, natural EPA chromone analogue $\mathbf{2 6}$ showed cellular protective effects of HepG2 cells against cellular lipid peroxidation (CLPAA assays), and reactive oxygen species (CAA assays) [62]. The activity of more lipophilic chromone $\mathbf{2 6}$ was similar to quercetin in the CLPAA assay (respectively $\mathrm{IC}_{50}$ : 14 and $10 \mu \mathrm{M}$ ) but was less active in the CAA assay (respectively $\mathrm{IC}_{50}: 160$ and $71 \mu \mathrm{M})$.

Most of the results reported in literature with the DPPH assay, are consistent with a decrease of radical scavenging capacity after 
introduction of a lipidic moiety on phenolic structure. However, different experiment performed in microsomial suspension, in emulsion system or in cellular media, may probably lead to different conclusions, regarding the capacity of lipophenol to maintain antioxidant activity and better protection in lipophilic biological or food system media. Additional in vitro and cellular assays must be necessary to fully address the question of lipophenol antioxidant activity.

\subsection{Anti-cancer activity}

Why using n-3 PUFAs to enhance anti-cancer activity of phenolic compounds? The answer could be explained by several rational points. First of all epidemiological studies pointed out that diet rich in n-3 PUFAs may lower proportion of cancer incidents. Indeed, n-3 PUFAs and PUFA metabolites are involved in various cellular processes that may help to lower tumor progression or to protect healthy tissues during chemotherapy: inflammation, cellular adhesion, energy metabolism, apoptosis signaling pathway... As an example, PUFA metabolites such as eicosanoids, resolvins or protectins are reported as potent anti-inflammatory derivatives that may affect tumor growth due to the close relation between inflammation and cancer. According to PUFA activities in this domain, it appears interesting to conjugate PUFAs to obtain a synergism with cytotoxic drugs. Moreover, it has been demonstrated that PUFA uptake is considerably elevated in tumor tissues, thanks to tumor-specific transport of HSA-bound complex. Here, PUFAs are used as biochemical precursors and energy sources for the cell. Based on this observation, PUFA conjugates are perfect candidates to not only investigate improvement in pharmacokinetics and distribution of poorly bioavailable drugs, but also acquire at the same time a specific accumulation of the cytotoxic drug in tumor cells and tissues.

Among lipophilic anti-cancer derivatives, the most studied was the one linked on doxorubicin drug (DOX), responsible for DNA intercalation and inhibition of topoisomerase II, which has been used for the treatment of various types of cancer. DOX-ALA and DOXDHA 24 have been developed to reduce systemic toxicity and enhance therapeutic index. In vitro activities of DOX-hyd-DHA (linked through a cleavable hydrazone bound, 24a) were lower than DOX against L1210 leukemia cell lines. Whereas, in vivo activities in mice models (mice injected with L1210 leukemia and B16 melanoma cells, IP administration, optimal dose $16 \mathrm{mg} / \mathrm{kg}$ and $30 \mathrm{mg} / \mathrm{kg}$ respectively) improved the lifespan, lowered the weight loss and doubled the tumor growth inhibition [63]. In the study reported by Effenberger et al. [64], DOX-hyd-ALA 24a showed an advantage in avoiding multidrug resistance induction. The cytotoxic mode of action was largely apoptotic in 518A2, HL-60, KB-V.1 and MCF-7 cancer cell lines. Involvement of caspase-3, -8 and -9 , were different depending on the tested cell lines. In addition, significant increase in ROS has been observed. However, saturated heptadecanoyl analogue reduced metabolic activity of the cell lines more than the unsaturated DOX-hyd-ALA. In parallel, Liang et al. [65] studied in vitro (MCF-7, MDA-MB-231, and HepG2) and in vivo (mice) activities of DOX-ALA and DOX-PA (palmitate) either linked through an hydrazone bound (DOX-Hyd-ALA 24a) or by the daunosamine residue (DOX-ami-ALA 24b). In this study, saturated or unsaturated fatty acid on the $3^{\prime}$ amino group lead to a decrease in antitumor activity compared to DOX and DOX-hyd-ALA. DOX-hyd-ALA showed the highest cytotoxicity, stability in bloodstream, and fastest release of DOX in acidic tumor cells. As observed by Huan et al. [25] for DOXami-ALA, increase in cytotoxicity of DOX-Hyd-ALA was correlated to rapid internalization/uptake of the PUFA conjugate compared to free DOX. Regarding DOX release, cellular uptake and cytotoxicity, DOX-Hyd-ALA presented an advantageous biological profile compared to DOX, DOX-PA or DOX-ami-ALA. To end, in vivo evaluation of DOX-hyd-ALA in tumor-bearing nude mice (IV administration $7.5 \mathrm{mg} / \mathrm{kg}$, compound in solution in normal saline containing $5 \% \mathrm{v} / \mathrm{v}$
PEG400), enhanced therapeutic efficacy of DOX with less systemic toxicity and greatly increased the content of DOX in tumor tissue with a significant decrease of its proportions in other organs.

Another inhibitor of DNA topoisomerase II, the 4' demethyl deoxypodophyllotoxin (DDPT 23), showed strong in vitro toxicity, but without in vivo activity. FA-DDPT have been synthesized with the hope that esterification with FAs would reduce the metabolic excretion and enhance its in vivo efficiency [27]. Despite a lower cytotoxicity in in vitro assays (A-549 and SK-MEL-2 cell lines), long chain FA (C16-C22) presented better in vivo antitumor activity (60 mg/kg) than short alkanoyl acid derivatives (C2-C6), probably due to an increased resistance to esterase, that delay the metabolic excretion of phenolic hydroxyl group. The number of double bonds seems to play a role in the in vivo and in vitro activities, with a different (positive or negative) correlation depending on the length of the FA.

Other examples can be described, such as Dohevanyl (DHA vanillyl amide 11), a PUFA analogue of capsaicin, that induced caspasedependent apoptosis MCF-7 cells (via a caspase-3 independent pathway), with better efficiency than capsaicin [26]. The conjugation of juglone (5-hydroxy-1,4-naphthoquinone) with unsaturated FA (21) was able to considerably enhance inhibition of DNA polymerase replicative $\alpha$ and mitochondrial $\gamma$, compared to the initial phenol [20]. The inhibition effect of acyl conjugates ranked as follow C18:1 > C20:5 > C22:5 > C18:2 > C18:3, with saturated derivative $\mathrm{C} 18: 0$ acyl juglone as active as the individual compound. The same influence of the FA part was observed for the growth inhibition of human colon carcinoma cultured cell (HCT116), suggesting that cancer cell growth prevention by those derivatives may be attributed to DNA polymerase inhibition. However, it is worthy of note that conjugation of cytotoxic derivatives with PUFA does not necessary lead to an increase of the activity. Ahn et al. [23] synthesized acyl shikonin analogues, including shikonin-ALA 22, which showed negligible DNA-topoisomerase I inhibition in a cell free enzymatic assay.

Significant ameliorations of in vitro and in vivo activities were also reported with flavonoid polyphenols. Rutin-ALA 5, allowed overcoming solubility problems compared to native compounds, and was able to decrease the production of VEGF, a regulator of tumor induced neoangiogenesis, in K562 lymphoblastoid cell lines [11]. In this assay, C18 fatty acid esters of rutin having one, two or three double bonds presented the same activities, and rutin was not active at all.

A mixture of EGCG and tetra/penta esters of DHA (1), was evaluated in azoxymethane-induced colonic carcinogenesis mice [31] (oral diet, supplementation in EGCG-PUFA 0.5\%). The mixture was able to reduce the total number of colon large colonic aberrant crypt foci (ACF), a predictive biomarker of colorectal cancer. Increased activity compared to EGCG was attributed to an improve lipophilicity, that may alters in vivo metabolism. Pro-inflammatory mediators such as nitric oxide synthase (iNOS) and cyclooxygenase-2 (COX-2), known to be involved in carcinogenesis promotion, were down-regulated by the mixture in a dose-dependent manner. Hypothesis of a synergism between the polyphenol and the FAs part is expressed by the author.

$5 \alpha$-reductases are microsomal enzymes, that catalyze the reduction of double bond of a variety of steroid derivatives, and which may be involved in development and progression of prostate cancer. Since EGCG and ALA have been identified separately to inhibit such enzyme, Hiipakka et al. [34] and Lin et al. [35] studied the activity of EGC-ALA conjugates 2 , replacing the gallate moiety by ALA or by its saturated analogue. Probably due to a combined functionality of both phenolic and PUFA parts, the EGC-ALA conjugate showed potent $5 \alpha$-reductase type $1 / 2$ inhibition ( $\mathrm{IC}_{50}=7 \mu \mathrm{M}$ for type 1 ) compared to EGCG, EGC $\left(\mathrm{IC}_{50}>100 \mu \mathrm{M}\right)$ or saturated stearate lipophenol $\left(\mathrm{IC}_{50}=42 \mu \mathrm{M}\right)$ in whole cell-assay. Results were different in cell free assay depending on the study performed. Unlike Lin et al. [35] who 
reported increased activity of EGC-ALA or EGC-stearate $\left(\mathrm{IC}_{50}=0.73\right.$ $0.78 \mu \mathrm{M})$ compared to EGCG $\left(\mathrm{IC}_{50}=6.29 \mu \mathrm{M}\right)$, Hiipakka et al. [34] presented a close significant activity for EGCG and EGC-ALA, and a weak inhibition using EGC-stearate.

Interesting results were reported by Siddiqui team [24,66], which tried for once, to enhance anticancer properties of n-3 PUFAs in breast cancer, by making phenolic ester. DHA and EPA esters of propofol 19, demonstrated greater potency for inhibiting cell growth (MDA-MB-231), slowing migration, increasing cellular adhesion, and initiating apoptosis compared to the combination of propofol with DHA or EPA. By comparing stability and activity of ester and amide analogues of propofol-DHA, it was demonstrated that first, this ester linkage should not be cleaved in biological media, and second, that the activity depends on this stability. Moreover, unlike free DHA activity, there was no observed effect on PPAR $\alpha$ or PPAR $\gamma$, suggesting that DHA-propofol action followed an independent mode of action (probably inhibition of histone deacetylase - HDAC).

Among the natural products, cytotoxicity of the ALAalkylresorcinol analogue $\mathbf{2 9}$ was observed on human breast cancer (MCF-7) and human lung cancer (NCI-H460) cell lines [50]. The n-6 LA analogue was equipotent compared to 29. After comparison with per-acetylated analogues it was concluded that free phenolic hydroxyl groups are required for the anticancer activity. Another natural lipophenolic AR (34), showed a growth inhibition on human colon cancer cell lines, HCT-116 and HT-29 (MTT assay) [53]. Saturated or longer carbon chain analogues were tested and the results seemed to indicate that increasing the length of the side chain diminished the inhibitory activity (range from $\mathrm{C} 17$ to $\mathrm{C} 25$ ) and the existence of one double bond at least improved the activity. However, according to the authors the anticancer effects of ARs were very limited.

\subsection{Interaction with endocannabinoid system}

Research of cannabimimetic that could modulate endogenous cannabinoid system (ECS), have prompted researchers to develop FA amide based on the anandamide structure. Bezuglov et al. [18] reported activity of dopamine-EPA and dopamine-DHA conjugates 12, showing significant in vivo activity (IP administration $10 \mathrm{mg} /$ $\mathrm{kg}$, compound in solution in physiologic saline/tween20 mixture) in the tetrad test (production of catalepsy, hypothermia, analgesia and inhibition of locomotion), used for evaluation of cannabimimetic properties of drugs. The results suggested that they belong to the family of CB1-cannabinoid receptor agonist, and highlight the importance of at least 4 double bonds in the chemical structure of cannabimimetic. In addition, Bisogno et al. [19] studied the biochemical properties of unusual n-3 PUFA-dopamine (stearidonoyl C18:4, eicosapentaenoyl C20:5, docosapentaenoyl C22:5) and ALAdopamine, and reported their inhibition of protein of endogenous endocannabinoid system such as fatty acid amide hydrolase (FAAH), and anandamide transporter, as well as the binding to cannabinoid receptor CB1. The presence of the catechol structure of dopamine is believed to stabilize the enzyme substrate complex in the active site of FAAH and enhance affinity with CB1.

Looking for the development of novel analgesic derivatives, Melck et al. [67] designed PUFA derivatives based on capsaicin and anandamide structures, able to interact with endocannabinoid receptors, while preserving their capability to activate vanilloid receptors (TRVP1). Among them, $N$-acyl-vanillyl-amide-ALA 11, inhibited anandamide accumulation (RBL-2H3 cells), was a weak inhibitor of FAAH, presented selectivity for CB1 vs. CB2 receptor and was able to interact with TRVP1. However, omega-6 analogue (C20:4, arvanil) was a better candidate to develop "hybrid" cannabinoid/ vanilloid agonist derivative. Following the same goal, $\mathrm{N}$-acyltetrahydroisoquinoline-DHA 9 was tested on TRPV1 receptor expressed in HEK293 cells and exhibited partial agonist effect [30].
Regarding natural lipophenols, maca extract, which presents weak concentration of macamide $\mathbf{2 7}$ (an analogue of $\mathrm{N}$-acyl-vanillylamide-ALA 11), exhibits in vitro and in vivo (IV administration in a mixture water/poly-vinyl-pirrolidone, $3 \mathrm{mg} / \mathrm{kg}$ ) neuroprotective activity, as reported by Pino-Figuera et al [68]. In addition, thanks to structural similarity to endocannabinoid, isolated macamide $\mathbf{2 7}$, has been found to interfere with different proteins of the ECS $[69,70]$ : inhibition of FAAH enzyme and moderate binding affinity for CB1 receptor. It was reported that those activities are significantly improved if the lipophilic chain is replace by the LA analogue. Contradictory results describing the importance of the methoxy group was presented depending of the research team and the test performed.

\subsection{Anti-inflammatory activity}

Various studies support beneficial effects of polyphenols in chronic inflammatory diseases that may be explained, in part, by inhibition of transcription factor NF-kB activation, involved in gene expression of pro-inflammatory mediators such as INOS and COX2. Since n-3 PUFAs and their metabolites are reported to exhibit an inhibitory effect on inflammation, Zhong et al. [32] evaluated the potency of a mixture of EGCG-DPA (docosapentaenoyl, C22:5n-3) tetra and penta esters 1 to inhibit the production of proinflammatory mediators, nitric oxide (NO) and prostaglandin $\mathrm{E}_{2}$ $\left(\mathrm{PGE}_{2}\right)$, in lipopolysaccharides (LPS)-stimulated murine RAW 264.7 macrophages. At a concentration ranges around $50 \mu \mathrm{g} / \mathrm{ml}$, EGCGDPA esters inhibited $\mathrm{NO}$ and $\mathrm{PGE}_{2}$ production in a greater extent than did the free FA. As observed for, pure EGCG-DHA, EPA and Stearic tetra esters, EGCG-DPA exhibited down regulation effect of iNOS and COX-2 biosynthesis, while DPA alone exerted insignificant effect on their transcription. Contribution of DPA to antiinflammatory activity may pass through a different mechanism. Enhance cellular absorption and additional contribution of the fatty acid side chain, are proposed to comment increase efficiency of lipophenols.

Greater inhibitory effect of the inflammatory cytokine TNF- $\alpha$ production, was also found using Juglone-PUFA 21 (DHA, EPA and ALA) compared to the juglone, in cultured mouse macrophage RAW264.7 [20]. Close activity was also observed for saturated analogues having C18 and C12 chain length, while C6, C2 and C3 derivatives were poorly active. Comparable activities were reported for those esters in a mouse ear inflammatory test, to reduce inflammation caused by 12-O-tetradecanoylphorbol-13-acetate (TPA).

Inspired by the discovery of C22 enone FA (EFOX, electrophilic oxo derivatives), DHA and DPA metabolites generated during inflammation process by COX-2, Dang et al. [29], compared the antiinflammatory activity of a wide range of $\mathrm{N}$-acyl FAs (saturated FA and PUFA) including $N$-acyl-dopamine 12, $N$-acyl vanillylamine $\mathbf{1 1}$, and their enone fatty acid analogues. $N$-acyl dopamine conjugates exhibited the most potent inhibitory activity on the production of NO, cytokines IL-1 $\beta$, IL- 6 and TNF- $\alpha$, in LPS-activated RAW264.7. The activity was strongly dependent on the nature of the fatty acid part, in the order, enone FAs, PUFAs, monosaturated and saturated FAs, suggesting the interest of PUFA metabolites in the activity of PUFA-phenols.

\subsection{Enzymatic inhibitor}

Some n-3 lipophenols have been investigated as enzyme inhibitors [12,13,21,22], using the lipid chain as hydrophobic part which would modulate the affinity for the enzyme. Interesting comparison of the tyrosinase enzyme inhibition of phloridzin and isoquercitrin esters ( 6 and 7) was performed using stearic, oleic (OA), linoleic (LA), ALA, EPA and DHA fatty acids [12]. The precursor phloridzin exhibited weaker tyrosinase inhibition as compared to 
isoquercitrin (at $1 \mathrm{mM}, 16 \%$ and 54\% respectively). In both cases, introduction of specific n-3 FAs in the polyphenol structure lead to a strong increase in inhibition potential. However, depending on the polyphenols studied, introduction of DHA or ALA did not influence the activity in the same way: phloridzin activity was especially enhanced using DHA (91\% of inhibition), while isoquercitrin needs ALA linkage to reach around $86 \%$ of inhibition on the same target. Surprisingly, inversion of PUFA i.e. used ALA on phloridzin and DHA on isoquercitrin, drops inhibitory activity below precursor's one. Depending on the polyphenol structure and their flexibility, the molecule must be able to adjust differently the position of the FA and the phenolic function to obtain better interaction with the active site of the enzyme. Moreover, number of double bonds in the lipidic chain will necessary change the flexibility of the lipophenol conjugate and thus influence its conformation. Those results highlight that for a same target, different kinds of PUFA may be beneficial to increase the affinity of polyphenolic drugs for the active site.

Among, serine protease enzymes, namely Trypsin, Thrombine, Urokinase and Elastase, the acylation of rutin with medium to long FA (C16-C22, including ALA 5), provide significant improvement inhibitory activity only on Thrombine protease [13]. Viskupicova et al., suggested that the enhanced hydrophobicity, would provide interaction with hydrophobic region of the enzyme. The hypothesis was supported by QSAR analysis, showing correlation (correlation coefficient 0.7 ) between inhibitory activity and molecular volume, polar surface area and number of hydrogen bond acceptors. The chain length (C16-C18) appears to be a deciding factor for the activity while the number of double bound was less significant.

Those reported enzymatic cell free assays, point it out that lipophenol derivatives might exert their activity not only by increasing cell membrane penetration or fostering a synergistic effect between the phenolic and the n-3 PUFA, but that the entire lipophenol structures might be indispensable and responsible for increasing bioactivity. In future, molecular modeling would have to confirm this fact. Moreover, extra or intracellular proteins that are reported to bind phenolic or PUFA derivatives (such as albumin, PPAR ...), should be considered has potential target to study the activity of this new kind of lipophenol derivative.

This reflection could also be supported by natural lipophenol activities, bearing a non-hydrolysable n-3 PUFA part. In vitro cell free assays of hemiketal spiralisone $\mathbf{2 5}$ and chromone $\mathbf{2 6}$ (both EPA analogues) highlighted inhibitory activities (with $\mathrm{IC}_{50}<10 \mu \mathrm{M}$ ) against kinase targets, casein kinase $1 \delta(\mathrm{CK} 1 \delta)$, cyclin-dependent kinase 5 (CDK5/p25) and glycogen synthase kinase $3 \beta$ (GSK3 $\beta$ ), which are involved in Alzheimer's disease [40]. Interestingly the crude alga $Z$. spiralis extract presented kinase inhibitory potency, most probably linked to the cumulative effect of multiple moderately potent spiralisone inhibitors. This effect was especially showed for the inhibition of $\beta$-secretase BACE which is also involved in Alzheimer's disease. In addition, another example is given by the reported activity of the natural alkenylphenol ALA-anacardic acid derivative $\mathbf{4 2}$ [71]. In order to reduce bacteria resistance to antibiotics, $\mathbf{4 2}$ was tested for its inhibitory activity on bacterial $\beta$-lactamases, enzymes responsible for the inactivation of $\beta$-lactam antibiotics. It proved its efficiency against $\beta$-lactamase enzyme of Escherichia coli JT4 (TEM1) $\left(\mathrm{IC}_{50}=5 \mu \mathrm{M}\right)$, and had a lower but significant level of inhibition against $\beta$-lactamases of $E$. coli $\mathrm{K} 12$ (PSE4) $\left(\mathrm{IC}_{50}=10.1 \mu \mathrm{M}\right)$, Enterobacter cloacae P99 $\left(\mathrm{IC}_{50}=16.5 \mu \mathrm{M}\right)$ and Pseudomonas aeruginose $\mathrm{A}\left(\mathrm{IC}_{50}=40.5 \mu \mathrm{M}\right)$. For the two last one, 42 displayed a better activity than the $\beta$-lactam drug clavulanic acid.

\subsection{Antibacterial and antiparasitic activities}

Several natural lipophenolic compounds showed antibacterial activities. In addition to inhibition of kinase, hemiketal spiralisone $\mathbf{2 5}$ and chromone $\mathbf{2 6}$ exhibited moderate growth inhibitory activ- ity $\left(\mathrm{IC}_{50}=2.5-10 \mu \mathrm{M}\right)$ against gram positive bacteria Bacillus subtilis (ATCC 6051 and 6633) [40]. The antibacterial properties of the crude $Z$. spiralis extract was more expended than isolated lipophenols. This could be explained by the cumulative concentration effect of multiple mildly bioactive spiralisones.

EPA-acylphloroglucinol derivatives $\mathbf{3 7}$ and $\mathbf{3 8}$ displayed antibacterial activity (measures of microbial growth inhibition), tested in vitro on Staphylococcus aureus and Bacillys subtilus [9]. The compound $\mathbf{3 8}$ bearing a methoxy group is more active than $\mathbf{3 7}$ for the inhibition of $S$. aureus, while $\mathbf{3 7}$ is more potent than $\mathbf{3 8}$ against $B$. subtilus. Moreover, anacardic acid derivative $\mathbf{4 2}$ showed pronounced antibacterial effects on Bacillus cereus, Streptococcus pyogenes and Mycobacterium fortuitum [51], as its LA analogue. According to mono-saturated and longer carbon chain derivative evaluations, it was reported that the antibacterial activity drops with the decreasing number of unsaturation and with the increasing number of carbon on the lipid chain. The natural compound $\mathbf{4 2}$ also displayed weak antibacterial activity against Gram-positive organism (Staphylococci spp) [71].

ALA-Anacardic acid derivative $\mathbf{4 2}$ is not only an antibacterial agent but presents also antiparasitic (molluscicidal) activity against the snail Biomphalaria glabrata $\left(\mathrm{LC}_{50}= \pm 1 \mathrm{ppm}\right)$, an intermediate host in the schistosome life cycle [51]. The tyramine derivative $\mathbf{2 8}$ displayed moderate antiprotozoal activity $\left(\mathrm{IC}_{50}=38 \mu \mathrm{M}\right)$ against Plasmodium falciparum as reported by Gutierrez et al. [46]. Complementary assays with synthesized analogues suggested that longer FA lead to increased antiplasmodial activity, while the presence of polar groups on the FA chain decreased the activity. The ALA-AR analogue $\mathbf{2 9}$ could also be considered as antiparasitic agent, as its LA analogue [50]. In vitro tests of $\mathbf{2 9}$ exhibited moderate activity $\left(\mathrm{IC}_{50}=25 \mu \mathrm{M}\right)$ against intracellular form of the parasite Trypanosoma cruzi (Chagas disease), and a significant activity $\left(\mathrm{IC}_{50}=0.6 \mu \mathrm{M}\right)$ against a unicellular kinotoplastid prozoane parasite Leishmania donovani (human visceral leishmaniasis). As observed for cytotoxicity activity (part 4.2.), free phenolic hydroxyl groups are required for the antiparasitic activity. It was also demonstrated the importance of the bis-allylic positions. Moreover, this compound showed a stronger antiparasitic activity compared to catechol, suggesting the importance of the lipid part in the activity. Another AR 32 displayed paralyzing effects on the nematodes Trichostrongylus colubriformis (infective larvae for sheep) [52]. It was less potent compared to LA analogue, and more active than the analogue trans n-3 $(Z, Z, E)$. Unfortunately, in vivo evaluation $(50 \mathrm{mg} / \mathrm{kg}$ ) showed a lack of activity probably due to enzymatic degradation, weak bioavailability and difference in life stage of the parasite.

While the mechanism of action of those natural lipophenols has not been entirely studied, the literature highlights their interesting biological properties as antibacterial and/or antiparasitic derivatives, suggesting that they may serve a defensive role in plants [58] and in human. Additionally, regarding antibacterial and antiparasitic activities of LA and saturated analogues of some of the reported lipophenols, the PUFA part on those compounds was not absolutely necessary to exert an activity.

\section{From administration to the cells}

As reported all along the review, biological activity of n-3 lipophenol has been mainly evaluated by in vitro (cellular or cellular free) assay, a few studies reported in vivo evaluations on mice or rats, but currently no clinical test on human is reported for such derivatives. For cellular assays, due to the weak solubility of lipophenols in aqueous media, the tests are performed using the solubility of compound in DMSO or Ethanol (with a final concentration below $0.1 \%$ ), that allows the lipophenol derivative to be solubilized in the cell culture medium and to access cell. To illustrate this fact, Huang et al. reported that despite weaker aqueous 
solubility, doxorubicine conjugated with ALA was taken up more rapidly and in greater amount by cancerous cell lines compared to free doxorubicine [25]. For in vivo administration, since DMSO an ethanol are not acceptable vehicle, the lipophenol could be dissolved in physiologic saline solution in the presence of PEG [35] or using small proportion of detergent such as Tween20 [18], to afford lipophenol solution able to be injected by IV or IP processes. Formation of complex with albumin, as performed in the case of PUFA administration [72], may also be an alternative for in vivo administration, since both PUFA [5,6] and polyphenol [73] are known to bind with several sites of albumin, without necessarily affecting their activity [74].

Once administrated, what would be the stability of those types of derivatives? Most of the n-3 lipophenol have been synthesized by forming an ester bound between the phenolic and the PUFA parts. After oral administration, lipophenol linked through ester linkage may probably be cleaved during the digestive process. One can imagine that they will be highly metabolized, or rapidly eliminated as are most of the polyphenols after oral ingestion. However Zhong et al. reported an increased activity of the EGCG-PUFA esters (1) compared to EGCG after oral administration [31]. Liang et al. studied the stability of DOX-hyd ALA 24a and DOX-ami-ALA 24b in rat serum [65]. The results clearly demonstrate the stability of the hydrazone and the amide bound that released less than $25 \%$ of Doxorubicine in $48 \mathrm{~h}$. Siddiqui et al. studied the stability of PropofolDHA (19), a diisopropylphenol conjugate of DHA, in human and mouse serum at $37{ }^{\circ} \mathrm{C}$ for $2 \mathrm{~h}$ [66]. Probably because of steric hindrance of the isopropyl groups, the ester linkage was not cleaved at all. However this could be different with other lipophenols, depending on the chemical structure of the compounds. In future it would be important to study their stability inside of the cell, in presence of cellular esterases.

In the systemic circulation, after IV or IP administration, the biodistribution of the lipophenol will necessarily depend on their ability to bind plasma protein. The degree of binding to the major plasma protein, albumin, may have consequences on the rate of clearance of metabolites and for their delivery to cells and tissues. One of the mechanism of free PUFA transport is based on their binding with HSA, allowing them to reach lipophilic membrane despite their poor solubility in water $[3,75]$. This major plasma protein is also able to extensively bind polyphenol depending on their chemical structure [73]. Acylation of polyphenol may probably decrease the affinity of the phenolic part for albumin but the PUFA part should be able to compensate this loss of affinity. Lipophenol binding to human plasma albumin has been reported for DOX-hyd-ALA 24a which presents a protein binding rate of $98.7 \%$. After IV administration ( $7.5 \mathrm{mg} /$ $\mathrm{kg}$ ) this compound was able to reach heart, liver, lung and kidney and specifically the tumor tissue $(12 \mu \mathrm{g} / \mathrm{g}$ of tissue). This result could be compared to the one of other PUFA conjugate, such as DHAPaclitaxel, which showed an extensive bonding with HSA (99.6\%) and was relatively stable in blood circulation despite ester linkage between the two parts of the conjugate. Stability and metabolization of each lipophenol derivative will necessarily depend on their chemical structure and remains to be investigated individually for each of them in order to adapt, linker, formulation, doses, way of administration, and reach optimum systemic concentration and cellular uptake.

\section{Conclusions and future directions}

Chemical structures of natural and synthetic n-3 PUFA phenol derivatives have been reviewed. The design of the entitled compounds is most of the time aiming at enhancing biological efficiency by increasing lipophilicity of naturally "water soluble" polyphenolic molecules. From the synthetic point of view, access to n-3 lipophenols is easily performed using classical coupling reagents used in organic chemistry. Efficient utilization of enzymatic system such as CALB lipase was used to perform controlled introduction of PUFA moiety on sugar residues of flavonoids. Chemical protection/ deprotection strategies have also been successful to access mono PUFA-polyphenolic conjugates. Regioselective functionalization of the phenolic part by the fatty acid(s) is a tedious task yet, even though enzymatic reactions are helpful for some positions. In future, screening and modification of enzymatic lipase would offer additional possibility for lipophenol synthesis. Moreover new pathways have to be explored in the field to successfully complete the full range of lipophenol derivatives using practical syntheses.

Regarding n-3 lipophenol evaluations, those derivatives have showed a wide range of interesting biological activities: antioxidant, anti-inflammatory, anti-cancer, anti-bacterial, anti-parasitic activities ... Depending on the target and on the lipophenol structures, the role of the n-3 PUFA part was significantly different and the beneficial effect of the introduction of the PUFA moiety has to be assessed. The question of the stability and the metabolization of n-3 lipophenolic structures in biological media have not been fully explored and additional studies must be performed in future to give a better understanding of in vitro and in vivo mechanisms of those PUFA-phenol conjugates, to highlight the role of each part in the observed activity. Further developments in this field should take into account the increasing amounts of evidence that non enzymatic oxidized polyunsaturated fatty acids (iso-, phyto- and neuroprostanes) are biologically potent compounds that could be considered to produce new series of active lipophenols.

Following the same goal, traditional medicinal chemistry approach should help to design selected linkers (covalent, hydrolyzable, ...) between the PUFA and the phenolic part depending on the way of administration and on the tissue to target. Appropriate formulations (albumin complex, emulsion, ...) of such derivatives will also help to modulate ADME profile and to increase therapeutic index of those new lipophenol derivatives.

\section{Acknowledgments}

The authors are grateful to Université of Montpellier for financial support.

\section{References}

[1] N. Siriwardhana, N.S. Kalupahana, N. Moustaid-Moussa, Health benefits of n-3 polyunsaturated fatty acids: eicosapentaenoic acid and docosahexaenoic acid, Adv. Food. Nutr. Res. 65 (2012) 211-222.

[2] J.P. Vanden Heuvel, Nutrigenomics and nutrigenetics of omega3 polyunsaturated fatty acids, Prog. Mol. Biol. Transl. Sci. 108 (2012) 75-112.

[3] R.P. Bazinet, S. Laye, Polyunsaturated fatty acids and their metabolites in brain function and disease, Nat. Rev. Neurosci. 15 (2014) 771-785.

[4] K.B. Pandey, S.I. Rizvi, Plant polyphenols as dietary antioxidants in human health and disease, Oxid. Med. Cell. Longevity 2 (2009) 270-278.

[5] B.X. Huang, C. Dass, H.Y. Kim, Probing conformational changes of human serum albumin due to unsaturated fatty acid binding by chemical cross-linking and mass spectrometry, Biochem. J. 387 (2005) 695-702.

[6] I. Petitpas, T. Grune, A.A. Bhattacharya, S. Curry, Crystal structures of human serum albumin complexed with monounsaturated and polyunsaturated fatty acids, J. Mol. Biol. 314 (2001) 955-960.

[7] M. Suh, A.A. Wierzbicki, E. Lien, M.T. Clandinin, Relationship between dietary supply of long-chain fatty acids and membrane composition of long- and very long chain essential fatty acids in developing rat photoreceptors, Lipids 31 (1996) 61-64.

[8] R. Pamplona, Membrane phospholipids, lipoxidative damage and molecular integrity: a causal role in aging and longevity, BBA Bioenergetics 1777 (2008) 1249-1262.

[9] W. Gerwick, W. Fenical, Phenolic lipids from related marine-algae of the order dictyotales, Phytochemistry 21 (1982) 633-637.

[10] B. Mbatia, S.S. Kaki, B. Mattiasson, F. Mulaa, P. Adlercreutz, Enzymatic synthesis of lipophilic rutin and vanillyl esters from fish byproducts, J. Agric. Food. Chem. 59 (2011) 7021-7027.

[11] F. Mellou, H. Loutrari, H. Stamatis, C. Roussos, F.N. Kolisis, Enzymatic esterification of flavonoids with unsaturated fatty acids: effect of the novel esters on vascular endothelial growth factor release from K562 cells, Process Biochem. 41 (2006) 2029-2034. 
[12] K.S. Ziaullah, S.N. Bhullar, H.P. Warnakulasuriya, Rupasinghe, Biocatalytic synthesis, structural elucidation, antioxidant capacity and tyrosinase inhibition activity of long chain fatty acid acylated derivatives of phloridzin and isoquercitrin, Bioorg. Med. Chem. 21 (2013) 684-692.

[13] J. Viskupicova, M. Danihelova, M. Majekova, T. Liptaj, E. Sturdik, Polyphenol fatty acid esters as serine protease inhibitors: a quantum-chemical QSAR analysis, J. Enzyme Inhib. Med. Chem. 27 (2012) 800-809.

[14] J. Viskupicova, M. Danihelova, M. Ondrejovic, T. Liptaj, E. Sturdik, Lipophilic rutin derivatives for antioxidant protection of oil-based foods, Food Chem. 123 (2010) $45-50$.

[15] M.M. Zheng, L. Wang, F.H. Huang, P.M. Guo, F. Wei, Q.C. Deng, C. Zheng, C.Y. Wan, Ultrasound irradiation promoted lipase-catalyzed synthesis of flavonoid esters with unsaturated fatty acids, J. Mol. Catal. B Enzym. 95 (2013) 82-88.

[16] A. Torres de Pinedo, P. Penalver, D. Rondon, J.C. Morales, Efficient lipase-catalyzed synthesis of new lipid antioxidants based on a catechol structure, Tetrahedron 61 (2005) 7654-7660.

[17] K. Sabally, S. Karboune, R. St-Louis, S. Kermasha, Lipase-catalyzed transesterification of dihydrocaffeic acid with flaxseed oil for the synthesis of phenolic lipids.J. Biotechnol. 127 (2006) 167-176.

[18] V. Bezuglov, M. Bobrov, N. Gretskaya, A. Gonchar, G. Zinchenko, D. Melck, T. Bisogno, V. Di Marzo, D. Kuklev, J.C. Rossi, J.P. Vidal, T. Durand, Synthesis and biological evaluation of novel amides of polyunsaturated fatty acids with dopamine, Bioorg. Med. Chem. Lett. 11 (2001) 447-449.

[19] T. Bisogno, D. Melck, M. Bobrov, N.M. Gretskaya, V.V. Bezuglov, L. De Petrocellis, V. Di Marzo, N-acyl-dopamines: novel synthetic CB(1) cannabinoid-receptor ligands and inhibitors of anandamide inactivation with cannabimimetic activity in vitro and in vivo, Biochem. J. 351 (Pt 3) (2000) 817-824.

[20] S. Maruo, I. Kuriyama, K. Kuramochi, K. Tsubaki, H. Yoshida, Y. Mizushina, Inhibitory effect of novel 5-O-acyl juglones on mammalian DNA polymerase activity, cancer cell growth and inflammatory response, Bioorg. Med. Chem. 19 (2011) 5803-5812.

[21] N. Matsuyama, T. Kosaka, M. Fukuhara, Y. Soda, K. Mizuno, Polyunsaturated fatty acid anilides as inhibitors of acyl-CoA : cholesterol acyltransferase (ACAT), Bioorg. Med. Chem. Lett. 9 (1999) 2039-2042.

[22] S. Pany, A. Majhi, J. Das, PKC activation by resveratrol derivatives with unsaturated aliphatic chain, PLoS One 7 (2012) e52888.

[23] B.Z. Ahn, K.U. Baik, G.R. Kweon, K. Lim, B.D. Hwang, Acylshikonin analogues: synthesis and inhibition of DNA topoisomerase-I, J. Med. Chem. 38 (1995) 1044-1047.

[24] K.A. Harvey, Z. Xu, P. Whitley, V.J. Davisson, R.A. Siddiqui, Characterization of anticancer properties of 2,6-diisopropylphenol-docosahexaenoate and analogues in breast cancer cells, Bioorg. Med. Chem. 18 (2010) 1866-1874.

[25] M.L. Huan, S.Y. Zhou, Z.H. Teng, B.L. Zhang, X.Y. Liu, J.P. Wang, Q.B. Mei, Conjugation with alpha-linolenic acid improves cancer cell uptake and cytotoxicity of doxorubicin, Bioorg. Med. Chem. Lett. 19 (2009) 2579-2584.

[26] N. Tuoya, Y. Baba, Y. Shimoishi, M. Murata, M. Tada, K. Koseki, Takahata, apoptosis induction by dohevanil, a DHA substitutive analog of capsaicin, in MCF-7 cells, Life Sci. 78 (2006) 1515-1519.

[27] Y.J. You, Y. Kim, N.H. Nam, B.Z. Ahn, Antitumor activity of unsaturated fatty acid esters of 4'-demethyldeoxypodophyllotoxin, Bioorg. Med. Chem. Lett. 13 (2003) 2629-2632.

[28] P. Burch, A. Chicca, J. Gertsch, K. Gademann, Functionally optimized neuritogenic farinosone C analogs: SAR-study and investigations on their mode of action, ACS Med. Chem. Lett. 5 (2014) 172-177.

[29] H.T. Dang, G.J. Kang, E.S. Yoo, J. Hong, J.S. Choi, H.S. Kim, H.Y. Chung, J.H. Jung, Evaluation of endogenous fatty acid amides and their synthetic analogues as potential anti-inflammatory leads, Bioorg. Med. Chem. 19 (2011) 15201527.

[30] D.K. O'Dell, N. Rimmerman, S.R. Pickens, J.M. Walker, Fatty acyl amides of endogenous tetrahydroisoquinolines are active at the recombinant human TRPV1 receptor, Bioorg. Med. Chem. 15 (2007) 6164-6169.

[31] Y. Zhong, Y.S. Chiou, M.H. Pan, C.T. Ho, F. Shahidi, Protective effects of epigallocatechin gallate (EGCG) derivatives on azoxymethane-induced colonic carcinogenesis in mice, J. Funct. Foods 4 (2012) 323-330.

[32] Y. Zhong, Y.S. Chiou, M.H. Pan, F. Shahidi, Anti-inflammatory activity of lipophilic epigallocatechin gallate (EGCG) derivatives in LPS-stimulated murine macrophages, Food Chem. 134 (2012) 742-748.

[33] Y. Zhong, F. Shahidi, Lipophilized epigallocatechin gallate (EGCG) derivatives as novel antioxidants, J. Agric. Food Chem. 59 (2011) 6526-6533.

[34] R.A. Hiipakka, H.Z. Zhang, W. Dai, Q. Dai, S.T. Liao, Structure-activity relationships for inhibition of human 5 alpha-reductases by polyphenols, Biochem. Pharmacol. 63 (2002) 1165-1176.

[35] S.F. Lin, Y.H. Lin, M. Lin, Y.F. Kao, R.W. Wang, L.W. Teng, S.H. Chuang, J.M. Chang, T.T. Yuan, K.C. Fu, K.P. Huang, Y.S. Lee, C.C. Chiang, S.C. Yang, C.L. Lai, C.B. Liao, P. Chen, Y.S. Lin, K.T. Lai, H.J. Huang, J.Y. Yang, C.W. Liu, W.Y. Wei, C.K. Chen, R.A. Hiipakka, S. Liao, J.J. Huang, Synthesis and structure-activity relationship of 3-O-acylated (-)-epigallocatechins as 5alpha-reductase inhibitors, Eur. J. Med. Chem. 45 (2010) 6068-6076.

[36] F. Mainini, A. Contini, D. Nava, P.A. Corsetto, A.M. Rizzo, E. Agradi, E. Pini, Synthesis, molecular characterization and preliminary antioxidant activity evaluation of quercetin fatty esters, J. Am. Oil. Chem. Soc. 90 (2013) 17511759 .

[37] C. Crauste, C. Vigor, P. Brabet, M. Picq, M. Lagarde, C. Hamel, T. Durand, J. Vercauteren, Synthesis and evaluation of polyunsaturated fatty acid-phenol conjugates as anti-carbonyl-stress lipophenols, Eur. J. Org. Chem. (2014) 4548-4561.
[38] I. Matuszewska, A. Leniewski, P. Roszkowski, Z. Czarnocki, Synthesis of a novel class of fatty acids-derived isoquinolines, Chem. Phys. Lipids 135 (2005) $131-145$.

[39] D.D. Wang, T.J. Girard, T.P. Kasten, R.M. LaChance, M.A. Miller-Wideman, R.C. Durley, Inhibitory activity of unsaturated fatty acids and anacardic acids toward soluble tissue factor-factor VIIa complex, J. Nat. Prod. 61 (1998) 1352-1355.

[40] H. Zhang, X. Xiao, M.M. Conte, Z. Khalil, R.J. Capon, Spiralisones A-D: acylphloroglucinol hemiketals from an Australian marine brown alga, Zonaria spiralis, Org. Biomol. Chem. 10 (2012) 9671-9676.

[41] C. Tringali, M. Piattelli, 2 chromone derivatives from the brown alga ZonariaTournefortii, Tetrahedron Lett. 23 (1982) 1509-1512.

[42] V. Amico, R. Currenti, G. Oriente, M. Piattelli, C. Tringali, A phloroglucinol derivative from the brownalga Zonaria-Tournefortii, Phytochemistry 20 (1981) $1451-1453$.

[43] R.P. Gregson, R. Kazlauskas, P.T. Murphy, R.J. Wells, New metabolites from brown alga Cystophora-Torulosa, Aust. J. Chem. 30 (1977) 2527-2532.

[44] R. Kazlauskas, L. King, P.T. Murphy, R.G. Warren, R.J. Wells, New metabolites from the brown algal Genus Cystophora, Aust. J. Chem. 34 (1981) 439-447.

[45] R.A. Barrow, R.J. Capon, Alkyl and alkenyl resorcinols from an Australian marine sponge, Haliclona Sp (Haplosclerida, Haliclonidae), Aust. J. Chem. 44 (1991) 1393-1405.

[46] M. Gutierrez, T.L. Capson, H.M. Guzman, J. Gonzalez, E. Ortega-Barria, E. Quinoa, R. Riguera, Antiplasmodial metabolites isolated from the marine octocoral Muricea austera, J. Nat. Prod. 69 (2006) 1379-1383.

[47] M.M. McCollom, J.R. Villinski, K.L. McPhail, L.E. Craker, S. Gafner, Analysis of macamides in samples of Maca (Lepidium meyenii) by HPLC-UV-MS/MS, Phytochem. Anal. 16 (2005) 463-469.

[48] T. Reffstrup, O. Hammershoy, P.M. Boll, H. Schmidt, Philodendron-scandens Koch Et Sello subsp oxycardium (Schott) Bunting, a new source of allergenic alkyl resorcinols, Acta Chem. Scand. B 36 (1982) 291-294.

[49] M. Tori, K. Nakashima, Y. Asakawa, Sesquiterpenes and a phenolic compound from the liverwort Omphalanthus-Filiformis, Phytochemistry 38 (1995) 651-653.

[50] C. Jimenez-Romero, D. Torres-Mendoza, L.D.U. Gonzalez, E. Ortego-Barria, K.L. McPhail, W.H. Gerwick, L. Cubillas-Rios, Hydroxyalkenylresorcinols from Stylogyne turbacensis, J. Nat. Prod. 70 (2007) 1249-1252.

[51] J. Corthout, L. Pieters, M. Claeys, S. Geerts, D. Vandenberghe, A. Vlietinck, Antibacterial and molluscicidal phenolic-acids from Spondias Mombin, Planta Med. 60 (1994) 460-463.

[52] S. Valcic, G.A. Wachter, C.M. Eppler, B.N. Timmermann, Nematicidal alkylene resorcinols from Lithraea molleoides, J. Nat. Prod. 65 (2002) 1270-1273.

[53] Y.D. Zhu, D.R. Conklin, H.D. Chen, L.Y. Wang, S.M. Sang, 5-Alk(en)ylresorcinols as the major active components in wheat bran inhibit human colon cancer cell growth, Bioorg. Med. Chem. 19 (2011) 3973-3982.

[54] G. Cefarelli, B. D’Abrosca, A. Fiorentino, A. Izzo, P. Monaco, Isolation, characterization, and antioxidant activity of E- and Z-p-coumaryl fatty acid esters from cv. Annurca apple fruits, J. Agric. Food Chem. 53 (2005) 3525-3529.

[55] M.E. Masaki, S. Hiro, Y. Usuki, T. Harumoto, M.N. Terazima, F. Buonanno, A. Miyake, H. Iio, Climacostol, a defense toxin of Climacostomum virens (protozoa, ciliata), and its congeners, Tetrahedron 60 (2004) 7041-7048.

[56] M. El Hattab, N. Bouzidi, A. Ortalo-Magne, Y. Daghbouche, M. Richou, S.E. Chitour, B. de Reviers, L. Piovetti, Eicosapentaenoic acid: possible precursor of the phloroglucinol derivatives isolated from the brown alga Zonaria tournefortii (JV Lamouroux) Montagne, Biochem. Syst. Ecol. 37 (2009) 55-58.

[57] H.F. Anwar, T.V. Hansen, First total synthesis of a polyunsaturated chromone metabolite isolated from the brown algae Zonaria tournefortii, Org. Lett. 11 (2009) 587-588.

[58] S.R. Baerson, J. Schroder, D. Cook, A.M. Rimando, Z. Pan, F.E. Dayan, B.P. Noonan, S.O. Duke, Alkylresorcinol biosynthesis in plants: new insights from an ancient enzyme family?, Plant Signal. Behav. 5 (2010) 1286-1289.

[59] A. Kozubek, J.H.P. Tyman, Resorcinolic lipids, the natural non-isoprenoid phenolic amphiphiles and their biological activity, Chem. Rev. 99 (1999) 1-25.

[60] M. Laguerre, E.A. Decker, J. Lecomte, P. Villeneuve, Methods for evaluating the potency and efficacy of antioxidants, Curr. Opin. Clin. Nutr. Metab. Care 13 (2010) 518-525.

[61] I. Pinchuk, H. Shoval, Y. Dotan, D. Lichtenberg, Evaluation of antioxidants: scope, limitations and relevance of assays, Chem. Phys. Lipids 165 (2012) 638647.

[62] Y.M.A. Mohamed, A. Vik, T. Hofer, J.H. Andersen, T.V. Hansen, Polyunsaturated fatty acid-derived chromones exhibiting potent antioxidant activity, Chem. Phys. Lipids 170 (2013) 41-45.

[63] Y. Wang, L. Li, W. Jiang, Z. Yang, Z. Zhang, Synthesis and preliminary antitumor activity evaluation of a DHA and doxorubicin conjugate, Bioorg. Med. Chem. Lett. 16 (2006) 2974-2977.

[64] K. Effenberger, S. Breyer, R. Schobert, Modulation of doxorubicin activity in cancer cells by conjugation with fatty acyl and terpenyl hydrazones, Eur. J. Med. Chem. 45 (2010) 1947-1954

[65] C.H. Liang, W.L. Ye, C.L. Zhu, R. Na, Y. Cheng, H. Cui, D.Z. Liu, Z.F. Yang, S.Y. Zhou, Synthesis of doxorubicin alpha-linolenic acid conjugate and evaluation of its antitumor activity, Mol. Pharm. 11 (2014) 1378-1390.

[66] R.A. Siddiqui, M. Zerouga, M. Wu, A. Castillo, K. Harvey, G.P. Zaloga, W. Stillwell, Anticancer properties of propofol-docosahexaenoate and propofoleicosapentaenoate on breast cancer cells, Breast Cancer Res. 7 (2005) R645R654.

[67] D. Melck, T. Bisogno, L. De Petrocellis, H. Chuang, D. Julius, M. Bifulco, V. Di Marzo, Unsaturated long-chain N-acyl-vanillyl-amides (N-AVAMs): vanilloid 
receptor ligands that inhibit anandamide-facilitated transport and bind to CB1 cannabinoid receptors, Biochem. Biophys. Res. Commun. 262 (1999) 275-284.

[68] A. Pino-Figueroa, D. Nguyen, T.J. Maher, Neuroprotective effects of Lepidium meyenii (Maca), Ann. N. Y. Acad. Sci. 1199 (2010) 77-85

[69] Z. Hajdu, S. Nicolussi, M. Rau, L. Lorantfy, P. Forgo, J. Hohmann, D. Csupor, J. Gertsch, Identification of endocannabinoid system-modulating N-Alkylamides from Heliopsis helianthoides var. scabra and Lepidium meyenii, J. Nat. Prod. 77 (2014) 1663-1669.

[70] H. Wu, C.J. Kelley, A. Pino-Figueroa, H.D. Vu, T.J. Maher, Macamides and their synthetic analogs: evaluation of in vitro FAAH inhibition, Bioorg. Med. Chem. 21 (2013) 5188-5197.

[71] N.J. Coates, M.L Gilpin, M.N. Gwynn, D.E Lewis, PH. Milner, S.R. Spear, J.W. Tyler Sb-202742, a novel beta-lactamase inhibitor isolated from Spondias Mombin, J. Nat. Prod. 57 (1994) 654-657.
[72] M.O. Trepanier, J. Lim, T.K. Lai, H.J. Cho, A.F. Domenichiello, C.T. Chen, A.Y Taha, R.P. Bazinet, W.M. Burnham, Intraperitoneal administration of docosahexaenoic acid for 14days increases serum unesterified DHA and seizure latency in the maximal pentylenetetrazol model, Epilepsy Behav. 33 (2014) 138-143.

[73] C. Manach, A. Scalbert, C. Morand, C. Remesy, L. Jimenez, Polyphenols: food sources and bioavailability, Am. J. Clin. Nutr. 79 (2004) 727-747.

[74] O. Dangles, C. Dufour, S. Bret, Flavonol-serum albumin complexation. Twoelectron oxidation of flavonols and their complexes with serum albumin, J. Chem. Soc. Perk. Trans. 2 (1999) 737-744.

[75] A.A. Spector, Plasma free fatty acid and lipoproteins as sources of polyunsaturated fatty acid for the brain, J. Mol. Neurosci. 16 (2001) 159165 